\title{
A linguagem da cerâmica Guaraní: sobre a persistência das práticas e materialidade (parte 1) ${ }^{1}$
}

\author{
The language of Guaraní pottery: about the persistence of \\ practices and materiality (part 1)
}

Francisco Silva Noelli²

José Proenza Brochado ${ }^{3}$

Ângelo Alves Corrêa ${ }^{4}$

DOI: https://doi.org/10.26512/rbla.v10i2.20935

Recebido em julho de 2018

Aceito em agosto de 2018

\section{Resumo}

Este artigo apresenta a linguagem da cerâmica registrada nos dicionários Tesoro $e$ Vocabulario de la lengua Guaraní, publicados respectivamente em 1639 e 1640 pelo missionário jesuíta Antonio Ruiz de Montoya. Selecionamos 445 palavras e frases para compor cenários etnográficos. Nosso objetivo é compreender a cadeia operatória de produção das vasilhas cerâmicas Guaraní e alguns dos contextos de seus usos domésticos. O léxico apresenta grande potencial para estudos de linguística histórica comparada com outras línguas do tronco Tupí e de tecnologia cerâmica arqueológica.

Palavras-chave: língua Guaraní, conhecimento tradicional, taxonomia cerâmica, tecnologia cerâmica

\begin{abstract}
This paper discuss the pottery language registered in the dictionaries Tesoro and Vocabulario de la lengua Guaraní, published respectively in 1639 and 1640 by the jesuit missionary Antonio Ruiz de Montoya. We selected 445 words and phrases to compose ethnographical settings. Our aim is to understand the operational sequence production of the Guaraní ceramic vessels, and some contexts of its domestic use. The lexicon presents great potential for comparative studies of historical linguistics about the Tupí languages and the archaeological pottery technology amongst.
\end{abstract}

${ }^{1}$ Dois artigos complementam este: 1) sobre o contexto geral da ocupação Guaraní (Bonomo et al., 2015); 2) sobre a arqueologia e linguística no caso dos povos Tupí (Silva e Noelli, 2017).

${ }^{2}$ Arqueólogo, professor aposentado, Universidade Estadual de Maringá. chico.noelli@, gmail.com

${ }^{3}$ Arqueólogo, professor aposentado, Universidade Federal do Rio Grande do Sul.

${ }^{4}$ Arqueólogo, professor do Curso de Arqueologia e Conservação em Arte Rupestre, da Universidade Federal do Piauí. angelo@ufpi.edu.br 
Keywords: Guaraní language, traditional knowledge, pottery taxonomy, pottery technology

"El tiempo es olvido y es memoria"

J L Borges

\section{Definindo o problema}

Neste artigo apresentamos uma compilação sistemática e interpretação da mais extensa lista de vocábulos e frases relacionados à cerâmica Guaraní. É um texto experimental construído a partir de dois dicionários, com os dados ordenados e articulados como cenários etnográficos, no sentido de compreender a cadeia operatória de produção da cerâmica e alguns de seus usos cotidianos. A fortuna de encontrar fontes linguísticas tão completas permitiu superar a imensa lacuna sobre o tema nas fontes históricas e etnográficas, resgatando preciosas informações coletadas no século XVII, em territórios ainda distantes do sistema colonial, entre populações que eram autodeterminadas e resistiam aos europeus nas bacias dos rios Paranapanema e Tibagi. Consideramos este trabalho apenas um começo, havendo muito para avançar no conhecimento do léxico e textos Guaraní fixados no dicionário, sendo necessária uma tradução alternativa com perspectivas linguística, etnográfica e tecnológica. Na próxima edição da RBLA publicaremos a segunda parte do artigo, no qual apresentaremos ilustrações referentes a este vocabulário para demonstrar que as regularidades linguísticas têm correspondência na tecnologia cerâmica, sendo possível propor uma teoria de que havia uma uniformização da linguagem da cerâmica em todos os assentamentos Guaraní até aqui estudados. Pode não haver tantos registros linguísticos, mas temos o registro arqueológico de milhares de sítios para demonstrar tal possibilidade. E, na perspectiva do presente, observando-se os registros etnográficos e entrevistando os Guaraní falantes dos três dialetos (Avá-Guaraní, Kaiowá e Mbyá), rapidamente constatamos que eles ainda mantêm os mesmos nomes para as suas vasilhas emblemáticas em centenas de assentamentos espalhados por vasta área.

Escrevemos movidos pela premissa de que os arqueólogos precisam compreender a importância dos conteúdos linguísticos quando investigam sociedades com línguas vivas ou documentadas. Neste caso a língua é um portal para vários níveis de interesse acadêmico e dos próprios Guaraní, sendo possível submergir até as estruturas profundas do conhecimento conservadas e transformadas na longa duração, ou seja, para reconhecer o legado da transmissão de conhecimentos de uma geração à outra, fixados nas palavras e nos modos de fazer e usar as coisas. Pensamos que foi esse legado que produziu e manteve a cultura material Guaraní com características muito específicas, com aparências e funções semelhantes entre os diversos povos falantes de várias das mais de 70 línguas do tronco Tupí. A arqueologia se faz também com e por meio de palavras, e foi isto que nos levou a investigar como as similaridades e 
transformações de conhecimentos permitem evidenciar persistências históricas no tempo (relacionando passado e presente), possibilitando gerar conhecimento acadêmico para auxiliar as demandas dos povos indígenas pela garantia do seu estilo de vida e manutenção ou reconquista das suas terras.

As nossas fontes são os dicionários bilíngues de Antonio Ruiz de Montoya, elaborados no seu serviço missionário jesuíta na Província do Paraguai. Nas 1062 páginas da quarta edição do Tesoro de la lengua Guaraní (1639) e do Vocabulario de la lengua Guaraní (1640), encontramos um léxico com 445 palavras e frases diretas e indiretas sobre matérias-primas, técnicas de produção, morfologia e uso das vasilhas cerâmicas. Por se constituir como vocabulário básico tão completo, também é referência para estudos de linguística histórica comparada entre os Tupí, como mostraremos na conclusão. $\mathrm{O}$ valor dos dicionários não é apenas linguístico. Uma das primeiras tarefas de um regime colonial é aprender a língua daqueles que se pretende colonizar (Guha, 1997). Assim, os dicionários eram guias enciclopédicos para facilitar o acesso dos missionários aos vários temas práticos e simbólicos da imensa população Guaraní, estimada no começo do século XVII em aproximadamente um milhão de pessoas apenas no Guairá, que incluía parte do atual Estado do Paraná (Melià, 1986:88). Montoya viveu entre 1611 e 1637 nas reduções e, em trânsito por diversas aldeias, observou o cotidiano dos Guaraní, registrando in loco o que havia de comum entre seus assentamentos, selecionando itens para compor os dicionários. Sem a padronização, os dicionários não fariam sentido para os religiosos conviverem com os Guaraní das regiões Centro-Oeste e Sul do Brasil, Nordeste da Argentina e Paraguai oriental. Então, a outra premissa que ancora esta investigação é o ñande reko (nosso modo de ser), a filosofia Guaraní de reprodução do seu modo de ser, como se verifica nos registros linguísticos, nas práticas cerâmicas e entre eles próprios na atualidade.

\section{Base de dados e metodologia}

As vasilhas cerâmicas são utilizadas em todo o mundo como marcadores geográficos e cronológicos na investigação arqueológica. Também são utilizadas para reconhecer diversos aspectos relacionados ao modo de vida, tecnologia, economia, sociabilidade, territorialidade e conhecimentos diversos, independentemente de registros escritos. Mas as fontes escritas possuem um papel fundamental na compreensão dos mais diversos aspectos de uma sociedade ao longo da história e, quando devidamente analisadas sob uma perspectiva interdisciplinar e etnoarqueológica, são importantes para o estudo de períodos recuados, anteriores a qualquer descrição histórica, etnográfica ou linguística. As fontes escritas, especialmente aquelas do período colonial, descrevem ações sociais e a vida social dos objetos (Galloway, 2006). No caso dos Guaraní, a documentação da linguagem da cerâmica oferece uma oportunidade para 
desenvolver vários temas de pesquisa, dentre eles, aquele do qual ora nos ocupamos: a cadeia operatória das cerâmicas e seus contextos de uso.

O nosso levantamento exaustivo nas quatro edições dos dicionários teve várias etapas entre 1987 e 2018, com a exploração exaustiva de todas as edições do Tesoro e do Vocabulario. Procuramos estabelecer uma metodologia para definir as classes funcionais das vasilhas inteiras e para reduzir o erro na reconstrução gráfica a partir de fragmentos de borda. A função de uma vasilha pode ser deduzida ou observada (La Salvia e Brochado, 1989:121). É deduzida quando não existe observação etnográfica, nem fontes escritas e dados iconográficos suficientes, sendo a sua interpretação hipotética a partir das proporções e dimensões da morfologia das vasilhas arqueológicas. É observada quando existe registro histórico ou etnográfico sobre sua tecnologia de produção e uso específico (primário ou secundário). A leitura de Montoya nos permitiu encontrar meios para deduzir e observar, pois oferece-nos informações plenamente compatíveis com as vasilhas arqueológicas e uma linguagem sobre tecnologia e funcionalidade da cerâmica.

A primeira edição consultada foi a de Francisco Adolfo de Varnhagen (Montoya, 1876a, 1876b), utilizada nos relatórios sobre a cerâmica do alto rio Uruguai, na publicação de artigos e do livro Cerâmica Guaraní (La Salvia et al., 1989; La Salvia e Brochado, 1989; Brochado, Monticelli e Neumann, 1990; Brochado e Monticelli, 1994). A partir de 1989 pesquisamos a versão de Julius Platzmann, fac-símile da primeira edição (Montoya, 1876c, 1876d), para estudos sobre a cultura material e ecologia (p. ex.: Noelli, 1993, 1994, 1998a, 1998b; Noelli e Dias, 1995; Noelli e Brochado, 1998). Para este artigo utilizamos as mais recentes edições coordenadas por Bartomeu Melià (Montoya, 2002, 2011), com o léxico transliterado por Antonio Caballos e Friedl Paz Grünberg, comparando cada palavra com cópias das primeiras edições do Tesoro (Montoya, 1639) e do Vocabulario (Montoya, [1640] 1994). Para tentar alcançar a plenitude dos significados do léxico, utilizamos dois dicionários espanhóis dos séculos XVII e XVIII, mas sem citá-los sistematicamente: 1) Tesoro de la lengua Castellana o Española (Covarrubias Orozco, 1611); 2) Diccionario de Autoridades, em seis volumes (1729-1739).

Para economizar na quantidade total de palavras do artigo, reduzimos o tamanho da citação das referências dos dicionários: 1) T:1 (Montoya, 2011, página 1); 2) B:1 (Montoya, 2002, página 1); 3) TLC:1 (Covarrubias Orozco, 1611, página 1); 4) DA 1:1 (Diccionario de Autoridades, volume 1, página 1). A citação da palavra ou frase Guaraní foi copiada integralmente como foi redigido por Montoya, em negrito seguida pelas referências T (Tesoro) e B (Vocabulario), o número da página e a tradução em espanhol grafada com itálico. Por exemplo: ña'ẽ'ũ (T:358; B:208) barro de loza. Também alertamos ao leitor que serão encontradas formas arcaicas no léxico e na composição das frases em espanhol. 
Revisamos e ampliamos o léxico de Montoya publicado para a investigação das classes funcionais de cerâmicas arqueológicas (cf. La Salvia e Brochado, 1989:115-145; Brochado, Monticelli e Neumann, 1990:730; Brochado e Monticelli,1994:107-108).Em1989, os objetivoseram:1)“fazerumaclassificação etno-histórica da cerâmica Guaraní do século XVII"; 2) "identificação destas classes entre as vasilhas Guaraní arqueológicas inteiras"; 3 ) "estabelecimento de regras de proporção entre as partes destas vasilhas, separadamente para cada classe"; 4) "uso destas regras na reconstrução gráfica através de fragmentos". Dito de outro modo, tratava-se de fazer a hermenêutica das fontes escritas; de compreender as morfologias das vasilhas a partir da definição das suas partes constituintes e a relação das formas com funcionalidades específicas. A abordagem cumpriu os objetivos propostos, legando uma nova maneira para investigar cerâmica arqueológica a partir de uma perspectiva interdisciplinar. $\mathrm{O}$ mais importante foi o método com efeitos positivos para mostrar a função das vasilhas e reduzir os erros na reconstrução gráfica baseada em perfis de vasilhas inteiras, confirmando o valor da morfologia como marcador para identificar os sítios ocupados pelos Guaraní. Inicialmente foi proposto um conjunto com 10 classes funcionais (Brochado, Monticelli e Neumann, 1990:730). Depois foi revisado e reduzido para 6 (Brochado e Monticelli, 1994:108): 1) panelas para cozinhar; 2) caçarolas para cozinhar; 3) pratos para assar beiju; 4) jarras para bebida em geral, especialmente para bebidas fermentadas alcoólicas; 5) pratos para comer; 6) tigelas para beber. Agora, ao prosseguir desenvolvendo o método e ampliando a base de dados, ainda consideramos que as morfologias do conjunto de vasilhas cerâmicas Guaraní ainda não foram definitivamente estabelecidas. Ao falarmos de vasilhas cerâmicas Guaraní, assumimos a presença de semelhanças estruturais e de proporções que podem ser mapeadas no espaço geográfico e datadas na longa duração. Além da forma, foram registradas as demais características preponderantes nas classes funcionais (quadro 1). 


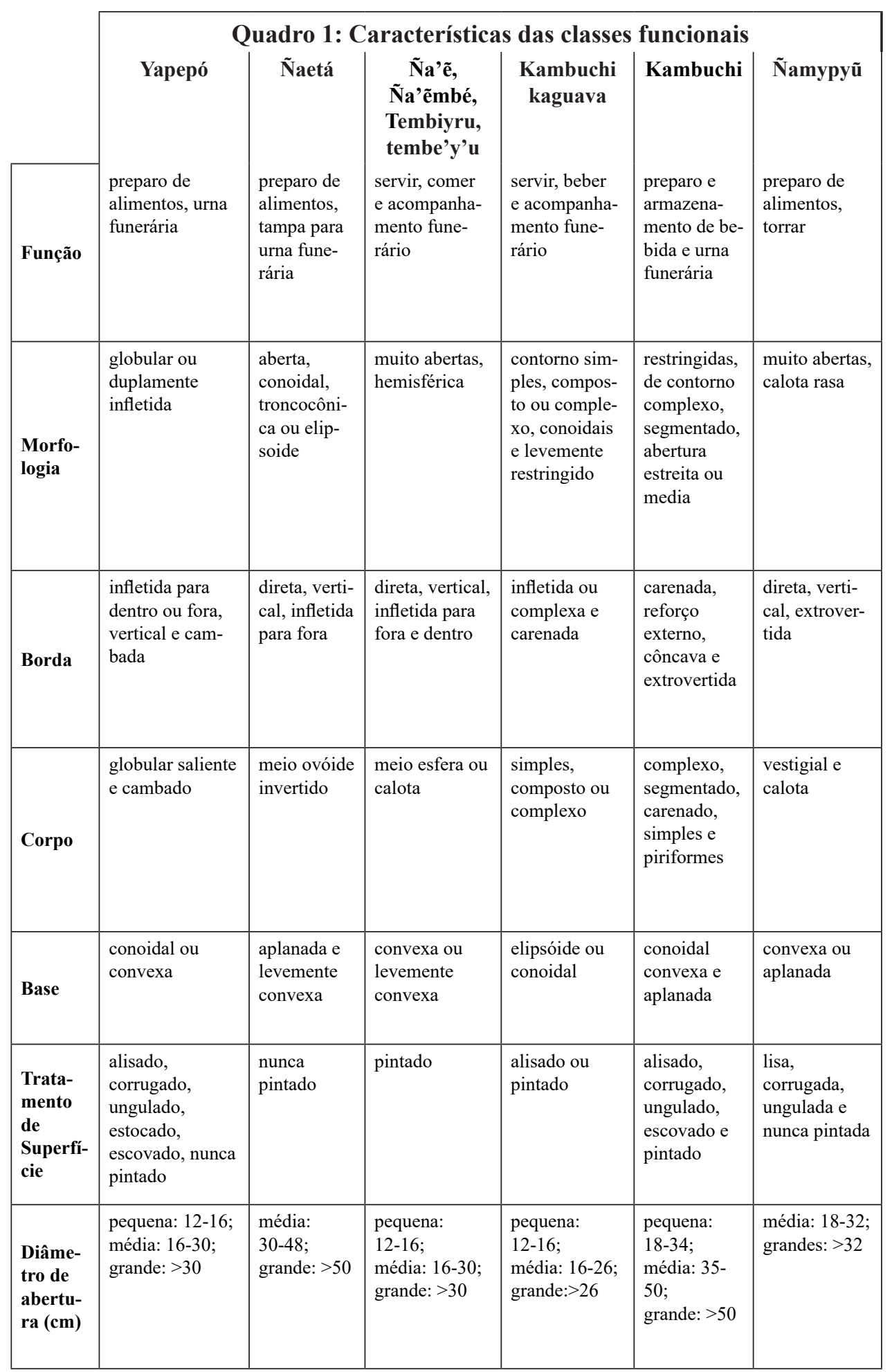

Para ampliar o alcance do primeiro objetivo citado acima, a nova leitura 
exaustiva e sistemática dos dicionários procurou: 1) levantamento e registro mais completo do léxico; 2) ordenação do léxico por temas; 3) análise contextual de aspectos tecnológicos e funcionais. Além das leituras, passados 30 anos do início do projeto, após suspender a pesquisa entre 1995 e 2009, retornamos ao levantamento de vasilhas inteiras e semi-inteiras nas coleções de instituições públicas, privadas e particulares. Entre 2011 e 2014, estivemos em 45 instituições de 15 Estados brasileiros, onde registramos 971 vasilhas Guaraní inteiras, além das produzidas por outras populações falantes das línguas Tupí (Corrêa 2014). De 2015 até meados de 2018, ampliamos a amostragem total para 1826 vasilhas, registradas em 150 coleções no Brasil, Paraguai, Argentina, Uruguai, Áustria, Inglaterra e Holanda (a Bolívia possui coleções que ainda não analisamos). Esta etapa de levantamentos será encerrada no final de 2018, para a publicação de um catálogo com a imagem de todas as vasilhas registradas, mais os dados métricos sobre morfologia, tratamento de superfície e espessura, e os mapas com a sua distribuição geográfica. Posteriormente, pretendemos continuar visitando instituições para prosseguir com os registros e deixar o catálogo como um instrumento público de pesquisas o mais completo possível.

A principal conclusão sobre a amostragem atual é a de que Montoya testemunhou a existência de um conjunto tecnológico e funcional que não é aleatório, considerando que as vasilhas dos distintos assentamentos não apresentam diferenças significativas. Ou seja, as vasilhas arqueológicas encontradas em uma vasta área de 5 países da Bacia Platina comprovam que houve um padrão tecnológico replicado a partir de uma estrutura de transmissão de conhecimentos de uma geração à outra. $\mathrm{O}$ catálogo que estamos preparando oferecerá informações abundantes para demonstrar que as vasilhas cerâmicas são a objetificação de uma série de conhecimentos tradicionais acumulados e compartilhados entre as ceramistas de várias gerações, ao longo de 2 mil anos, conforme as várias datações dos sítios arqueológicos (Corrêa, 2017). Portanto, agora existe mais consistência para propor que a linguagem da cerâmica Guaraní registrada no século XVII possa ser aplicada para dar nome às vasilhas encontradas em qualquer um dos 4.815 sítios arqueológicos registrados até o presente.

O Montoya e outros cronistas dos séculos XVI e XVII testemunharam uma magnitude demográfica enorme, que aparece parcialmente mapeada com registros arqueológicos na figura 1 . O mapa arqueológico apresenta a distribuição dos sítios e ocorrências, revelando as principais áreas de concentração e vazios de investigação em espaços importantes, densamente povoados nos século XVI e XVII, como o Paraguai Oriental e partes do Mato Grosso do Sul. Também revela problemas a serem resolvidos, como ocorrências aparentemente isoladas nas áreas campestres ao redor do Rio da Prata e próximas de Santa Fé, provavelmente resultado das relações entre os Guaraní do baixo rio Uruguai e ilhas do Delta do rio Paraná com as diversas populações que viviam na região 
antes deles chegarem.

O colapso causado pelo impacto das epidemias levou os Guaraní a uma redução demográfica que ainda não foi devidamente compreendida, tampouco pesquisada. O desafio para todos investigadores das mais diversas disciplinas é compreender explicar como tanta gente conseguiu produzir uma cultura material e um modo de ocupar o espaço com tantas semelhanças, e como conseguiu manter uma língua comum em milhares de assentamentos por tanto tempo. Mesmo em áreas de contato permanente com populações de outras culturas. Como pesquisadores acostumados a investigar contextos com pouca gente, geralmente em uma única aldeia, poderão conceber uma avaliação que dê conta de uma vasta área densamente povoada por gente atuando sob as balizas do ñande reko? 


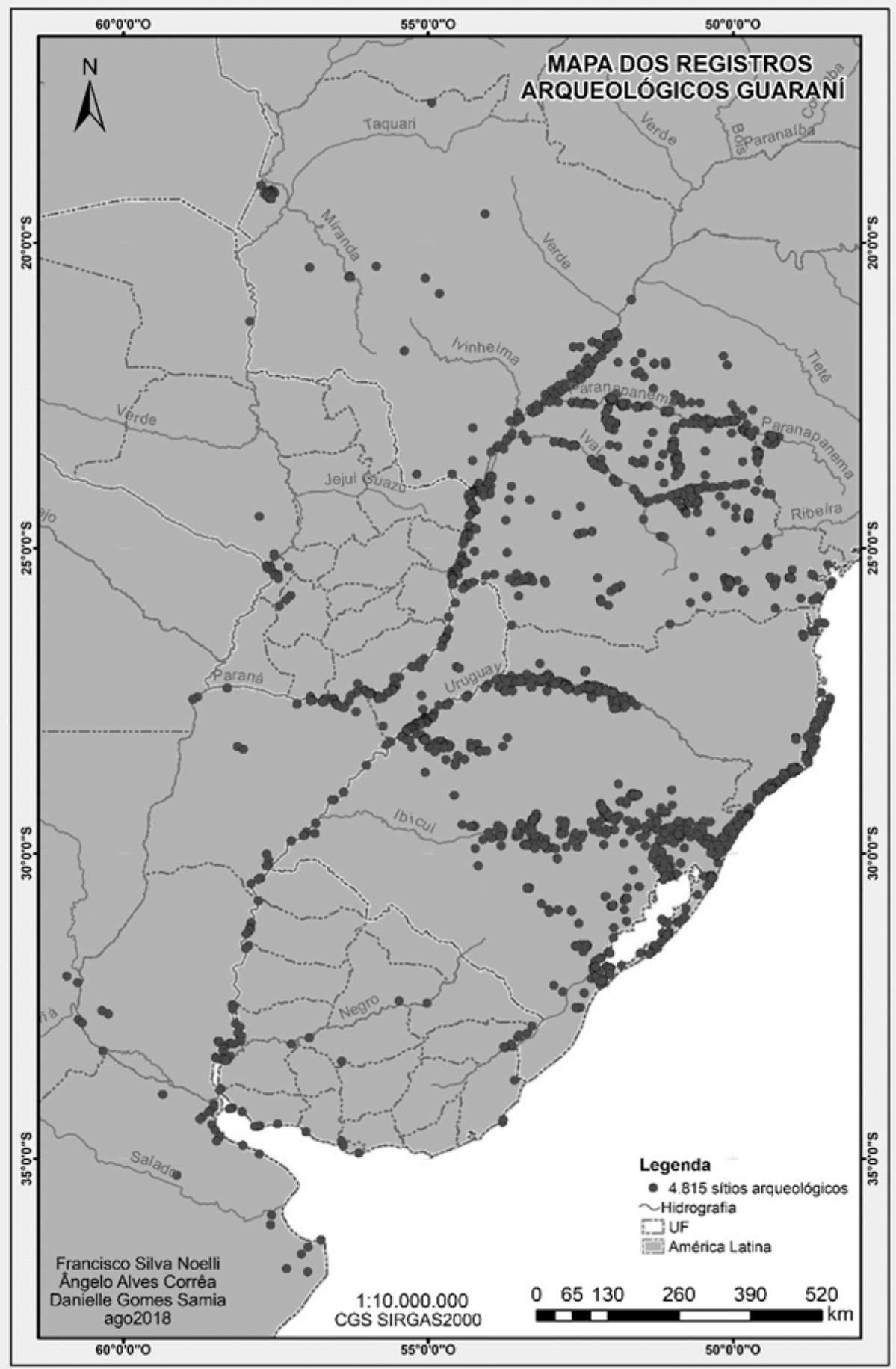




\section{Práticas de consumo e classes funcionais}

A língua Guaraní possui uma definição mais ampla e inclusiva para qualquer tipo de recipiente: como cestos, cabaças, bolsas tecidas, incluindo a cerâmica. Trata-se das palavras ryru ou yru (T:506, 641, B:394) vaso, vasija, cesto, continens, etc. A palavra latina continens pode ser traduzida literalmente como "coisa que contém" (contenedor, em espanhol). O dicionário da época de Montoya oferece para vaso três acepções relativas à função: 1) nombre genérico, por cualquier instrumento idóneo para recibir dentro de si alguna cosa; 2) más comúnmente que todos, en el que bebemos; 3) otros que son para la cocina y para las cosas inmundas (TLC:65v).

A única vasilha que agrega o termo genérico ryru em seu nome é o prato, justamente por servir a comida, definido como tembiyru, tembe'y'u (T:358, 506, 558, B:322) plato (tembi'u (T:558) comida; tembi'u + yru = comida + continens). Encontramos exemplos do emprego do nome ryru na guaranização dos nomes de vasilhas europeias: 1) mba'e ryhũ ryru; tyhũ ryru (B:380) tintero; 2) ty ryru (B:66) bacinilla; 3) tepotihápe, tepoti ryru (T:563, B:66) bacín o servicio; 4) juky ryru (T:219) salero; 5) y rovasapy ryru (B:321) pila de agua bendita.

Outras vasilhas europeias também foram definidas com nomes Guaraní:

jepohéitáva (T:426) aguamanil

tataendy (T:533, B:87) candela (T:533) fuego encendido

tataendy rendáva (T:533, B:246) lámpara

iraity rataendy; tataendy iraity reheguára (T:533, B:87) candela de cera tataendy renda; tataendy rupáva ( $\mathrm{T}: 533, \mathrm{~B}: 87)$ candelero

mbaka kyra rataendy (T:533, B:87) candela de sebo

A compreensão do vocabulário de Montoya exige o conhecimento das definições da língua espanhola no século XVII. Encontramos no Tesoro de la lengua Guarani as palavras vasija, botija, botijuela, cántaro, tinaja, tinajón, olla, cazuela, jarro, copa, escudilla, plato e tostador, para nomear as classes funcionais das vasilhas cerâmicas, mas não as suas definições. Para sanar as ausências, fomos aos seis volumes do Diccionario de Autoridades (1727-1739), publicados 90 anos depois dos dicionários de Montoya. Com este levantamento elaboramos os quadros 2 e 3, com a relação entre as classes funcionais e as definições do século XVIII. As ilustrações das vasilhas são uma amostra simplificada, sem escala, de cada classe funcional. 
Quadro 2: Classes funcionais de vasilhas e suas definições

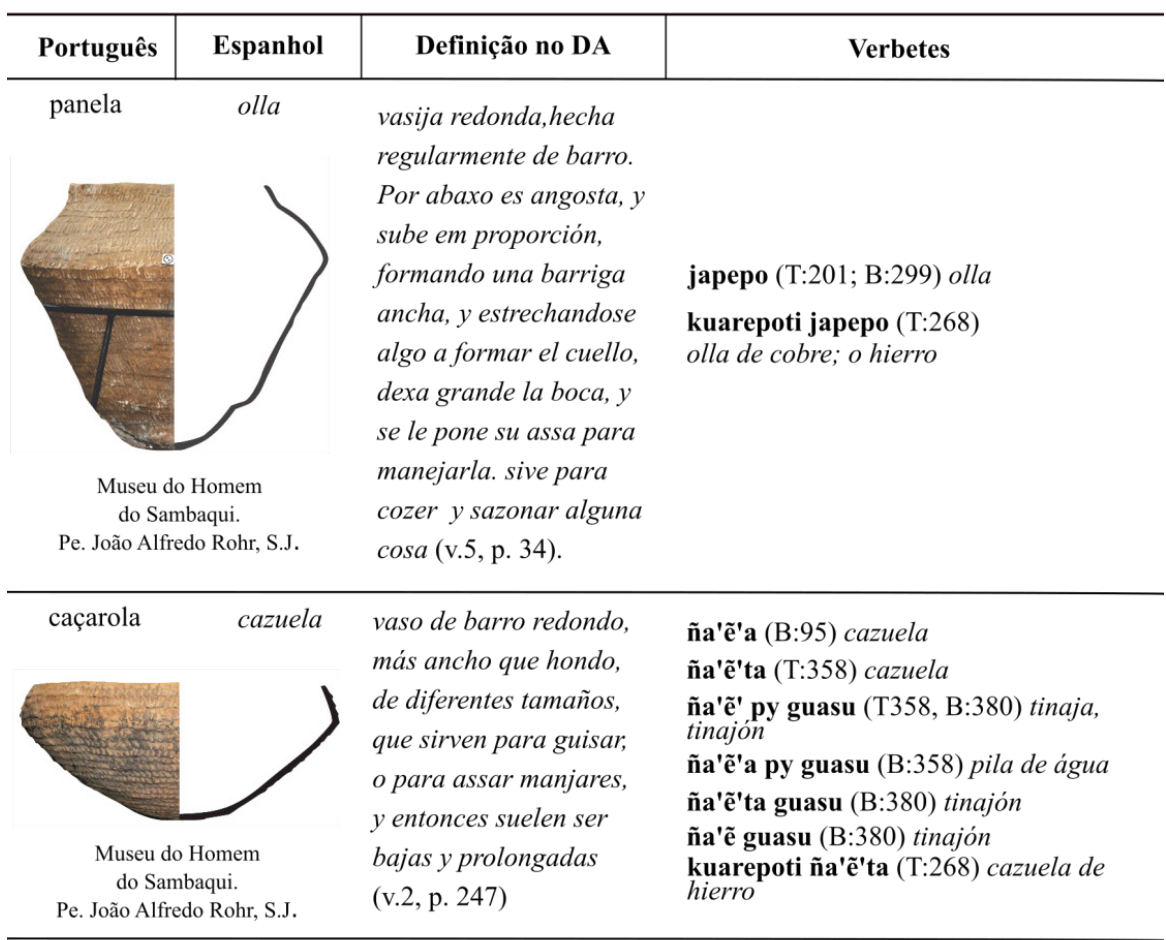

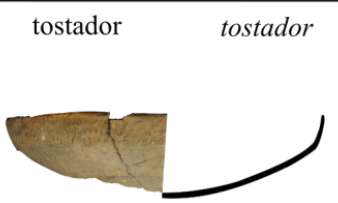

Museo de la Fundación

Carlos Alberto Pusineri Scala el que tuesta. Se llama asimismo el instrumento, em que se tuesta alguna $\cos a$ (v.6, p. 310). ñamypyũ (T:359; B:95) cazuela, tostador ñamypyũ guasu (T:359) tostador grande ñamypyũ (T:228) horno, cazuela grande

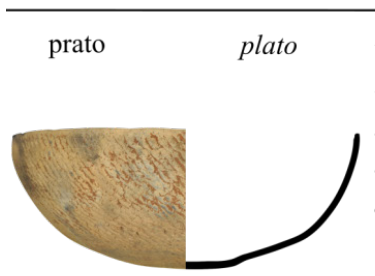

Museo Etnográfico Andres Barbero vasija baxa y redonda, com una concavidad en médio, y un borde o alero al rededor. Hacese de diversos tamaños... usase dél en las mesas para servir las viandas, comer nél, y para otros usos (v.5, p. 294)

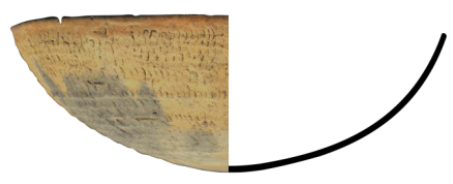

Divisón de Arqueología del Museo de La Plata ña'ẽ (T:358) cosa cóncava

ña'ẽ (T:358) plato

ña'ẽmbe (T:358, B:322) plato, plato de barro

teña'ẽ (T:358) plato "reciben muchos nombres"

tembyru, tembe'y'u (T:358, 558, B:322) plato

mbiporu (T:331, 448) cosa usable, lo que se usa, y lo toman por él plato comunment. ña'ẽpy guasu (T:358) tinaja

ña'ẽ apu'a (T:358) escudilla (tijela de madeira para comida)

ña'ẽmbe repysã (T:564) plato que tiene por medio divisiones

yvyra ña'ẽ (T:358) plato cóncavo yvyra ña'ẽmbe (T:358, B:322) plato de palo, de madera

kuarepoti ña'ẽmbe (T:268, 358, B:322)

plato de plata o peltre

ña'ẽmbe imoendypúpy (T:358) plato vidriado

ña'ẽmbe ikuatiapyre (T:358) loza pintada 
Quadro 3: Classes funcionais de vasilhas e suas definições

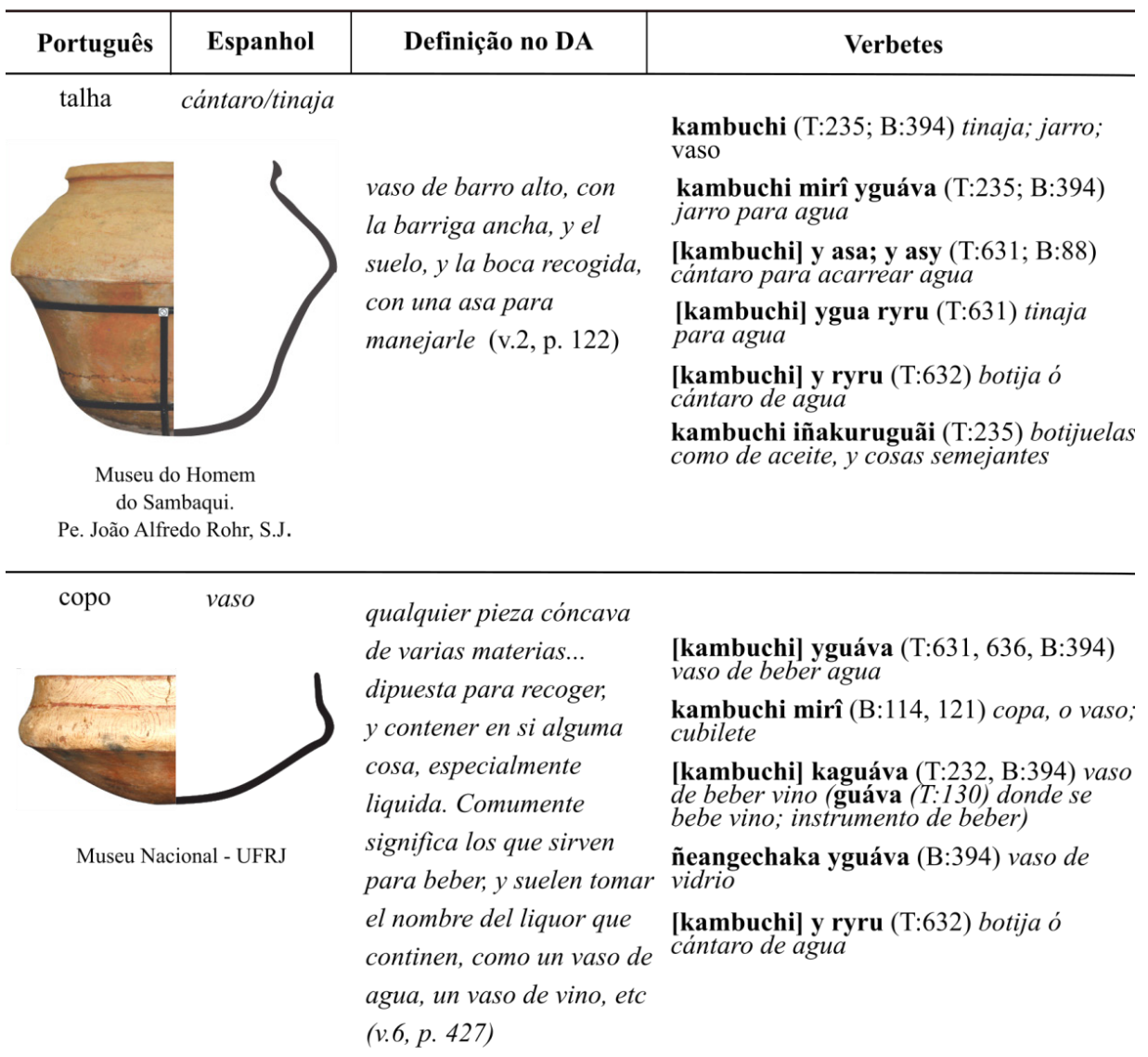

\section{Cadeia Operatória: quem, com o que e como se fazem cerâmicas}

\section{A oleira}

A confecção cerâmica era uma atividade feminina entre os Guaraní, seguindo o exemplo da maioria dos falantes das línguas do tronco Tupí (Pauke, 1943:15660; Azara, 1904:28-9; D’Orbigny, 1944:134; Métraux, 1928). O termo apohára (B:215) hacedor, era utilizado para falar sobre quem desenvolvia alguma atividade. $\mathrm{O}$ ato de trabalhar com a argila para fazer vasilhas foi dicionarizado como ña'ê'ũ apohára (B:299) ollero. Aparecendo ainda nas formas japepo apohára (T:201) ollera e, no ato de fazer pratos, definido como tembiyrurãma ajapo (T:558) hago platos. 


\section{A matéria-prima}

As vasilhas foram predominantemente confeccionadas com matérias inorgânicas na pasta cerâmica e nos pigmentos. Eventualmente, algumas superfícies pintadas bem preservadas apresentam uma camada de resina vegetal, aplicada após a queima da vasilha. As jazidas eram encontradas em distâncias variadas, próximas ou distantes dos assentamentos, sendo a sua determinação um tema inteiramente aberto à pesquisa. Em Montoya, encontramos as designações dos sedimentos utilizados como matéria-prima:

Ña'ê'ũ (T:358, B:208) barro negro de loza e barro de loza. Barro devia abranger um largo espectro de sedimentos argilosos e síltico-argilosos ricos em matéria orgânica, estes últimos encontrados em locais alagadiços e cursos de água. Montoya não usou a palavra arcilla. Parece-nos que o vocábulo ũ verbalizava o barro nos depósitos naturais e, somente depois de processado e preparado para a produção de vasilhas, receberia a denominação de ña' ề̃u.

Ña'ẽ'ũ tĩ (T:358) barro de loza, blanco. Sedimentos com diversos níveis de concentração de feldspatos cálcicos decompostos, normalmente misturados com os sedimentos argilosos e síltico-argilosos que compõem a pasta, dando-lhe coloração esbranquiçada.

É importante distinguir ña'ẽ'ũ de tuju (T:595; B:254). Tuju foi traduzido como lodo, cosa podre, o sedimento rico em matéria orgânica encontrada no tuju tĩ (T:595; B:254) lodazal, nas áreas alagadiças. Não existe registro do tuju sendo empregado puro na formulação da pasta cerâmica Guaraní e nem da sua adição em pequena proporção.

Tovatĩ (T:591, B:69) barro blanco. É o caulim, basicamente empregado na pintura branca da superfície da vasilha, tanto na face externa, quanto na interna.

Tapytã (B:69) barro colorado. Embora não apareça o qualificativo barro de louça neste verbete, os sedimentos argilosos e síltico-argilosos areníticos avermelhados foram comumente empregados na confecção das vasilhas, tanto na pasta, quanto na barbotina e no banho (La Salvia \& Brochado, 1989:17-18). A cor vermelha: 1) pytã, pirã [virã] (T:419, B:102) colorado; 2) moropytãnga'i (B:102) colorado fino.

Ita pytã (T:176) bermellón é a cor vermelha atribuída ao Óxido de Ferro, usada tanto nos banhos, quanto nas linhas vermelhas.

Os sedimentos usados para elaborar o pigmento negro não foram informados por Montoya. A cor preta: hũ, ñũ (T:176, 378, B:102) negro, color negro.

Os sedimentos com textura grossa e excesso de antiplástico eram denominados ña'ê' ũ ei (T:358) barro no fino (e'ii (T:118) muchos, significa a proporção de grãos acima do desejado). Este barro de granulometria maior seria trabalhoso na preparação da pasta, levando à necessidade de extrair grãos minerais até alcançar a proporção esperada entre o volume de sedimento e a quantidade de grãos.

Por outro lado, quando a argila possuía uma plasticidade muito acentuada a 
oleira acrescentava substâncias antiplásticas na pasta, como informa o verbete amoñã ña'ế'̃u ytaky pe ku'i pype (T:358) poner mezcla al barro. Neste caso, a pasta recebia ytaky pe ku'i (farelo de arenito triturado). Além do emprego de grãos minerais, as análises mostram variação no antiplástico: cerâmica moída (chamote), biominerais (carapaças de moluscos), fragmentos orgânicos, etc.

Ahumbiri ita pytã ikuatia haguãma (T:176) moler bermellón para pintar . Esta frase possivelmente refere-se a moer o óxido de ferro ita pytã (pedra vermelha), até virar pó, para ser hidratado e elaborar a tinta mineral vermelha.

\section{A preparação da pasta cerâmica}

Não há na bibliografia Guaraní informações etnográficas específicas sobre a extração do barro para a confecção cerâmica. Porém, existem duas referências de Félix de Azara do final do século XVIII: uma delas refere-se às ceramistas do Paraguai colonial no povoado de Itá, as quais coletavam sedimentos de "greda negra nos vales e lugares fundos" (Azara, 1904:28); a outra, também no Paraguai, nas canhadas com sedimentos "amarelados-pardos ou enegrecidos" (Azara, 1943:20). A extração dos sedimentos seria realizada com paus de cavouco, a exemplo dos Guaraní e de outros povos indígenas brasileiros (Noelli, 1993; Silva, 2000).

Os sedimentos poderiam ser transportados para o local da confecção das vasilhas dentro de envoltórios de folhas colocados em cestos-cargueiros, canoas, etc (Silva 2000). Na residência da ceramista havia o ña'ẽũnga (T:358) el lugar del barro, onde eram guardados os yvy apu'a trazidos da jazida. Esta seria uma área de atividade específica para fazer as vasilhas.

O verbete yvy apu'a (T:648) bodoque de barro (yvy = terra-barro; apu'a $=$ redondo-esfera), representa a elaboração das bolas de terra para o transporte. Yvy akytã (T:648) bodoque, terrón, seria o torrão natural de tamanho variado.

Com os sedimentos trazidos para o local da confecção das vasilhas, a oleira realizava uma sequência de processos para fazer a pasta, produzindo "uma relação entre argila e antiplástico", segundo La Salvia \& Brochado (1989:17). Isto é, dependendo das características físicas do sedimento, se acrescentavam ou retiravam elementos minerais e orgânicos. Além disso, para manter sua plasticidade, era importante induzir certos níveis de umidade na pasta durante a confecção da vasilha.

Montoya registrou o processo de amassar e abrandar os sedimentos, removendo o que chamou de impurezas (vegetais, torrões e grãos, de tamanhos indesejados de minerais, etc). O ato de "fazer barro" e preparar a pasta cerâmica era ayvy mboruru (T:649) ablandar tierra; hacer barro. Ele incluía retirar manualmente as impurezas: 1) amou'ũ (B:4) ablandar barro; 2) amboyku (B:4, 148) desleir, ablandar desliendo (yku (T:638) derretir, no sentido de dissolver). Neste processo a pasta era hidratada, ação descrita como amboruru, 
amou' ũ (B:5) ablandar mojando.

A expressão geral aikambi (B:147-148) deshacer con la mano, magullar; e as palavras específicas amonguruvichog e aikuruvichog (T:281, B:148) deshacer los tolondroncillos (terrones, tolondrones), referem-se a desmanchar torrões entre os dedos. Enfim, o objetivo era remover os kuru e kuruvi (T:281, B:312) pedazos e pedazuelos, divididos entre os grãos minerais (ita kuruvi T:281 piedras pequeñas) e torrões (yvy akuru T:281 terrón de tierra).

Depois de limpa e preparada, a etapa final de preparação da pasta é descrita pelo verbo ajuka (T:24) aporrear, sobar, amasar. Especificamente: 1) ajajuka ก̃a'ẽ'ũ (B:37) amasar barro; 2) ajapajuka ña'ẽ'ũ (B:69) hacer barro de loza. Quando o barro estava amassado, pronto, diziam ña'ẽ'ũ ijajukapýra (T:358)

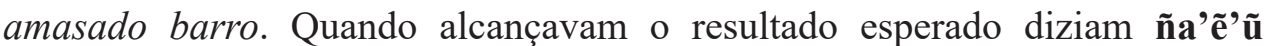
ijajuka katupýra (T:24) bien amasado; quando não era o desejado, diriam ña'ẽ'ũ ndijajuka katuhávi (T:24) no está bien amasado.

\section{Modo de produção ou receita de ação}

A vasilha era feita da base para a borda. Uma expressão caracterizava o início da atividade: ahevirũ japepo (T:502) dar princípio el ollero a la olla que hace. A oleira construía as paredes com a superposição de roletes (cilindros) de pasta cerâmica. A confecção dos roletes era denominada aikyty ña'ẽ' ũ (T:358) estirar el barro para hacer ollas (kyty T:288 refregar, no sentido de esfregar com a mão, girando a argila sobre uma base para fazer o rolete).

No processo de sobrepor e unir os roletes, a ceramista vai gradativamente levantando a parede, obliterando os roletes, ajustando a espessura desejada e dando a forma esperada. Os ajustes para deixar a vasilha com a forma desejada vêm descritos no verbete amoangu'a pypuku kambuchi (T:51) ensanchar el ollero el vaso por de dentro; isso exemplifica os ajustes da forma da peça durante a confecção, procurando-se "alargar, afundar, aprofundar" segurando um implemento para espalhar a pasta e mesclar a argila de vários roletes. De ambopyguasu ( $\mathrm{T}: 456)$ ensanchar, ampliar a capacidade alargando e aprofundando, como se estivesse escavando um pilão (anguá (T:51) mortero + pypuku (T:475) hondo, no sentido de o tornar mais espaçoso e aumentar o seu volume).

\section{Anatomia da vasilha}

O conteúdo dos dicionários mostra a analogia que os Guaraní faziam entre a anatomia humana e a morfologia da vasilha, assim como ocorria com a própria tradição Ibérica de onde vinha Montoya. O corpo é a barriga, a abertura é a boca, a borda é o lábio, o pescoço é o espaço entre a abertura e parte mais larga da vasilha. A base da vasilha equivale ao mesmo tempo a pé e terra, uma vez que suelo traduz-se como solo, chão, fundo e pé, mas também significava bunda 
ou nádegas. A vasilha, quando recebia um conteúdo, "agarrava", "pegava” ou "tomava" o que era colocado dentro.

O tamanho das vasilhas era dividido em três classificações gerais: grande, médio e pequeno (Tabela 1). Não há nomenclatura para tamanhos intermediários. A designação de tamanho vem como sufixo da palavra referente da vasilha: panela grande, caçarola média, prato pequeno, etc.

A tradução de grande é guasu (T:13, B:209) grande; grueso; ancho; e sua apócope é usu (T:615) grande, largo.

O tamanho médio é definido como voja [voñã] (T:624, B:272) mediano; menor.

O menor tamanho se traduz como mirĩ (T:308, B:315) poco; pequeño; chico. Com o mesmo significado de mirĩ existe, acentuada com variação, a palavra ti’i ou ti’ĩ (T:581) cosa chica (lo mismo que: mirĩ). Também há, com os significados de pequeno e pouco, a palavra michĩ (T:307).

Tabela 1: Exemplos da definição de tamanho

\begin{tabular}{c|l|l} 
Tamanho & \multicolumn{1}{|c|}{ Vasilha } & \multicolumn{1}{c}{ Função } \\
\hline \multirow{4}{*}{ Grande } & japepo guasu (T:201) & Olla grande \\
\cline { 2 - 3 } & ña'ẽmbe guasu (T:358) & Plato grande \\
\cline { 2 - 3 } & ña'ẽmbe pyko'ẽ guasu (T:358) & Plato grande hondo \\
\cline { 2 - 3 } & kambuchi guasu (T:235) & Tinaja grande \\
\hline Médio & japepo voja (T:201) & Olla media \\
\hline \multirow{3}{*}{ Pequeno } & japepo mirĩ (T:201) & Olla pequeña \\
\cline { 2 - 3 } & ña'ẽmbe mirĩ (T:358) & Plato pequeño \\
\cline { 2 - 3 } & kambuchi mirĩ yguava (T:235) & Jarro para agua
\end{tabular}

\section{Base: a "bunda da vasilha"}

A base era a primeira parte elaborada da vasilha, formando a peça inicial onde seriam aplicados os roletes para compor o corpo. A peça era feita com roletes ou modelada a partir de uma bolota de argila. Se a vasilha fosse pequena seria integralmente feita sem apoio, apenas com as mãos. Se fosse média ou grande, na maioria dos casos, por causa do diâmetro e do peso relativo das peças, primeiro seria moldada em uma concavidade escavada no solo com a forma desejada, como observamos nas marcas do perfil do terço inferior de centenas de vasilhas arqueológicas. O nome genérico de buraco é kuára (B:229) hoyo, de kua (T:263) agujero, hoyo, pozo. Para fazer o buraco é ambokua (T:263) hacer hoyo. A expressão adequada na descrição da escavação do molde para dar forma à base da cerâmica é amboapykyraguy (B:173) engrandar el hoyo por de dentro a la redonda, com o sentido de alargar o buraco, de (B:24) agrandar 
hoyo, comiendo alrededor.

A área da vasilha que tocava o piso era genericamente designada como topyta (T:585) cuento; testero; extremo, como está representado em ña'ẽmbe ropyta (T:585) suelo de plato. A face externa da base era definida como tevi (T:576) asiento, extremo por de fuera e (B:288) nalgas (uma analogia com nádegas, bunda). Por exemplo: japepo revi (T:576) el suelo de la olla por defuera. Também poderia ser por dentro da vasilha (T:201) el suelo de la olla por dentro, y fuera. A face interna da base era definida como hugua, rugua $\mathrm{e}$ tugua (T:176, 503, 593) testero; asiento; culata; popa; por de dentro. Por dentro a base da vasilha era denominada como japepo rugua (T:201) asiento de la olla por de dentro. É muito interessante a inclusão da tradução de "nádegas", pois bunda é uma analogia para a base que aparece para outros povos falantes das línguas da família Tupí-Guaraní, como é o caso dos Asurini do Xingu (Silva, 2000:64).

As coleções mostram três tipos básicos para forma da base, vistas pela face externa: 1) conoidal;2) arredondada; 3) plana (respectivamente denominadas por Montoya como pontiagudas, redondas e chatas). A existência dos três conceitos Guaraní para as bases é uma importante advertência aos arqueólogos, pois, quando reconstroem graficamente a forma das vasilhas a partir de fragmentos de borda, tendem à generalização do formato globular da base, especialmente os que seguem as sugestões de Ford (1962) e Meggers e Evans (1970) (cf. análise crítica in LaSalvia e Brochado, 1989:115-116).

As conoidais eram denominadas como tevicha akua (T:577) asiento puntiagudo de cántaro, fruta, etc. O formato vem de chuã (T:112, B:25) cosa aguda; olla; cesto; etc. As expressões amboevicha akua kambuchi (T:577) hacer cántaros con el suelo puntiagudo; kambuchi evichuã (T:112) botijuela puntiaguda en el fondo; japepo revichuã (T:201) olla con el suelo algo puntiagudo.

As arredondadas recebiam a designação de kambuchi apu'ã (T:235) vaso redondo; japepo revi agua (T:201) olla de suelo redondo; hevi'a jere kambuchi (T:576) olla redonda por el suelo. Inclusive a convexidade de alguns pratos tinha nome ipytepo rai ña'embe (T:482) tiene el plato barriga en medio.

As bases planas eram designadas como revi'a, traduzidas como "chatas". Por exemplo, kambuchi revi'a (T:576) suelo de cántaro chato. A confecção desta forma era descrita como amboevi'a (T:576) hacer chato el suelo del cántaro.

A forma da base está diretamente relacionada aos usos das vasilhas. Para ficar em pé e não tombar, algumas necessitavam ser enterradas por alguns centímetros e outras teriam apoio externo com aparatos de cerâmica, lítico, trançados e a própria lenha, no caso das panelas preparando o alimento. Montoya oferece alguns exemplos sobre os apoios: amboeviguy (T:576) poner 
algo debajo del cántaro sobre que asiente. Os apoios eram chamados de ita kuru (T:188, 189) piedras; bodoques de barro (que ponen debajo las ollas por trébedes). Na língua castellana os apoios das tinajas eram denominados reposadero e savilla (Torres, Gómez e Ferreira, 1997:126). Havia também um suporte de palha para algumas vasilhas, denominado patagui (T:398) asiento de paja para los vasos.

As vasilhas, especialmente as com base conoidal, eram apoiadas ou parcialmente enterradas para que pudessem permanecer equilibradas perpendicularmente em relação ao solo. Existe uma descrição de cântaros Guaraní semienterrados com bebidas fermentadas alcoólicas para servir, feita por Cabeza da Vaca (1906:327-28): "Ihes mandou dar de beber de umas talhas que tinham dentro de casa, mantidas até o pescoço de baixo da terra, cheias de vinho de milho".

E, ainda, sobre movimentar uma panela: ehugua upi japepo (T:593) levanta la olla por el asiento. Esta forma de movimentar a vasilha explicaria dois exemplos sobre quebrar a base da vasilha de dentro para fora: japepo rugua pog (T:593) quebrose el asiento de la olla; japepo rugua ambopog (T:593) quebrose el asiento de la olla; quité el asiento de la olla.

\section{"Barriga": a morfologia}

Ao traduzir corpo como barriga, Montoya mostrou literalmente a definição e o significado Guaraní: a (B:69) barriga de ollas; japepo a (T:1) la barriga de la olla. Nos dicionários indicou duas acepções para a (T:1): 1) coger, que em português significa agarrar, pegar, tomar; ou seja, a vasilha agarra, pega ou toma o seu conteúdo; 2) corpórea cosa, define a corporalidade da vasilha.

Montoya procurou fazer o leitor compreender a morfologia inserindo vários verbetes, que foram reorganizados abaixo em uma sequência para oferecer a compreensão Guaraní da morfologia.

O termo mais genérico para morfologia da vasilha é gua (T:125) cosa redonda. $\mathrm{O}$ verbete gua contém a indicação para consultar no Tesoro o termo pygua (T:470), cuja primeira acepção é abolladura e, a segunda, cosa en arcada. Atualmente pygua é traduzido como côncavo (Guash e Ortiz, 1986:113).

Logo, py + gua define simultaneamente forma e volume, cujo conceito equivalente da matemática é o sólido geométrico. Py (T:455) = centro; capacidad; vacío, é a noção Guaraní de volume, de capacidade, a área interna oca do sólido, como explicam os verbetes: 1) ña'ẽmbe py (T:358) la capacidad del plato por de dentro; 2) ña'ẽ py guasu (B:380) tinajón, uma vasilha de volume grande $(\mathbf{p y}=$ volume + guasu $=$ grande $)$. O conteúdo da vasilha é definido como pypia e po (T:474, B:112) lo contenido; contenido en la cosa, tendo como exemplos: 1) japepo pypiára (T:474) lo que está en la olla; 2) kambuchi po (T:431) lo contenido en el cántaro. 
Montoya destacou a perspectiva Guaraní, de quem observa a vasilha, com termo agua'a (T:11) abolladura (mirado por de fuera) e gua'a (T:125) abolladura por de fuera. O exemplo aparece na expressão japepo gua'a (T:125) la barriga de la olla por de fuera. Deriva do verbo amassar, ajambogua (B:5) abollar vaso, etc, com o sentido de dar forma ao corpo da vasilha, ajeitando os roletes com os dedos ou uma ferramenta para modelar a parede e seus tratamentos de superfície. Um exemplo para a barriga: ipytepo rai ña'embe (T:482) tiene el plato barriga por el medio.

O termo abolladura traduz-se por amolgadura ou amolgamento, isto é, dar forma curvada elou arqueada. E logo exemplifica com a expressão ambopygua kambuchi (T:470) hacer el ollero barriga a los vasos, repetindo o exemplo dado no verbete pygua, na segunda acepção, como "coisa em arcada". A expressão kambuchi ipygua (T:470) esta abollada la olla, o cántaro. E, na mesma página, seguindo o verbete pygua, Montoya colocou o verbo pyguarĩ (T:470) arquear.

Logo conclui-se que Montoya, ao reunir no mesmo grupo de verbetes os termos para uma forma côncava arredondada e arqueada, procurou mostrar que não se tratava simplesmente de vasilha com corpo arredondado e/ou arqueado, mas perfis com formas variadas e complexas cujas definições mais detalhadas estavam além do escopo do seu dicionário. Montoya utilizou a noção Guaraní mais inclusiva para volumes com formas variadas, indo além das globulares, para cada classe funcional. Isto é: 1) a variedade de perfis entre todas as classes funcionais de panelas, talhas, caçarolas, pratos, etc.; 2) a variedade entre as vasilhas de uma classe funcional, como as panelas.

La Salvia e Brochado (1989:116) consideraram que na cerâmica Guaraní "não existem vasilhas cuja forma se aproxime sequer suficientemente de esferas, cones, elipsoides, etc, para justificar a comparação" com um sólido geométrico. Eles escreveram que, "por outro lado, chama a atenção o aspecto representado pela maioria das vasilhas Guaraní. Tem-se a impressão que as ceramistas Guaraní concebiam as vasilhas como um empilhamento de zonas ou segmentos horizontais bem demarcados", definindo os segmentos como "unidades padrão, de formas definidas que sobrepostas, darão o contorno da vasilha" (La Salvia e Brochado, 1989:116).

A forma do corpo da vasilha, indicando toda a extensão do perfil, também foi registrada: japepo pykyraguy (T:456, 473) lo convexo de la olla. Pykyraguy e pykuraguy (T:456, 473), significam: lo de dentro de la cosa, los lados de la cosa por de dentro; lo convexo. Nestes dois verbetes Montoya não foi exato, por engano seu ou por erro tipográfico, trocando côncavo por convexo (como já observaram La Salvia e Brochado, 1989:127). Mas se encontra a correção no Tesoro e no Vocabulario, nos verbetes (')ẽ (T:116) hueco cóncavo e guy (B:107) cóncavo, com Montoya remetendo o leitor para o Tesoro, para ver pykyraguy. 
Se traduz convexo por pyko'ẽ (T:472), pyko'ẽngue (B:113).

Havia algumas vasilhas que Montoya definiu como ceñidas (apertadas, cingidas, acinturadas), com vários exemplos no mesmo verbete: kuái (T:266) cuello; cosa ceñida; kambuchi iku'a kuái (T:266) vaso ceñido por la cintura. Encontramos o ato de fazer a cintura na vasilha: amboku'a kuái kambuchi (T:266) ceñir asi el vaso. As acinturadas ocorrem entre as vasilhas com tamanhos médios e pequenos, provavelmente para estocar água, a exemplo de uma moringa.

\section{Borda e abertura: a "boca"}

A abertura da vasilha era denominada boca: kambuchi revicha (T:577) la boca de la olla. Há alguns verbetes que se referem à abertura como sinônimo de boca (juru (T:220, B:74) boca), referindo-se ao tamanho do seu diâmetro:

Pequeno: 1) jurumi (T:222) boca chica (mirĩ (T:308) poco; pequeño; chico); 2) kambuchi juru'ĩ; kambuchi jurumĩ (T:235) vaso de boca pequeña; 3) ambojuruvi kambuchi (T:220) hacer chica la boca al cántaro;

Médio: 1) juru voja (T:220) boca mediana (voja [voñã] (T:624) mediano); 2) kambuchi ijuru vojávae (T:220) olla de boca mediana; 3) ambojuru voja (T:220) hacer la boca mediana;

Grande: guasu (T:130) grande; grueso; ancho. Embora existam vasilhas arqueológicas com aberturas grandes ou largas, Montoya não fez registro específico sobre elas.

Há um registro para vasilha de pescoço comprido e abertura pequena, semelhante à cantimplora: juru ovi (T:222) cuello largo; boca chica, como de cantimplora. E outro sobre a altura da vasilha: ambopytepo katu ña'embe (T:482) dejar algo alto el medio del plato. O pescoço foi definido como la parte superior y más angosta de alguna vasija, cómo redóma, tinaja, \& etc. Collum (DA 2:679, DA 5:261).

A face interna do pescoço era definida como juko'ẽ (T:219, B:299) la olla del garguero (deve haver enganolinversão tipográfica, o correto seria el garguero de la olla). É o espaço entre a borda e o começo do ombro, na parede interna. Na época de Montoya, se definia garguero (TLC:429v) como o interior de la garganta; um século depois apareceu definido com mais detalhe: la parte interior de la garganta; por donde desciende de la boca el alimento a el estómago (DA 4:26).

Registramos e mensuramos mais de 2 mil vasilhas e verificamos que a forma 
da boca em todas as classes é predominantemente circular. Em menor proporção eram ovaladas, com um eixo maior e outro menor, sendo a maioria resultado de uma deformação ocorrida na elaboração ou na queima, mas percebe-se que a intenção era fazer circular. $\mathrm{O}$ verbete japepo rova rami (T:590) la manera que es la boca de la olla, registra a circularidade da abertura da vasilha, pois no mesmo grupo de verbetes está a expressão "circularidade do escudo": guarakapa rova rami (T:590) del círculo de una rodela (tova amã (T:586) círculo + rami (T:489) manera; tamaño; semejante).

O final do perfil da parede na abertura da vasilha era definido como: 1) pepo (T:406) bordos de cualquier cosa; 2) tembe e tembe'y (T:557, B:245, 301) lábio de abajo e orilla. Montoya exemplificou com as expressões: 1) ña'ẽmbe pepo (T:406) bordo de plato; 2) ña'ẽmbe rembe (T:358) bordo de plato; 3 ) japepo rembe (T:201) el labio de la olla; 4) ña'ẽ rembey (T:557) orilla de plato; 5) japepo rembey (T:201) el labio de la olla (que sale al modo de cuello hacia arriba, o como el labio de la bacinilla). A outra tradução de pepo é asa (T:406).

Algumas vasilhas para processar alimentos e conter líquidos passaram a receber um par de asas no período colonial. As talhas para conter água ou cauim traziam seus nomes com o sufixo nambi: kambuchi nambi (T:235) vaso con asas. A tradução literal em Guaraní não é asa, mas outra parte da anatomia da mastofauna: nambi (T:342) oreja.

As bordas possuíam diversos ângulos de inclinação, conforme a classe da vasilha (Brochado; Monticelli \& Neuman, 1990:732-737). Há um exemplo de Montoya para um tipo de ângulo da borda da panela: japepo rembey (T:201) el labio de la olla, que sale al modo de cuello hacia arriba, o como el labio de la bacinilla. Segundo La Salvia \& Brochado (1989:127), este verbete indica que a parede e a borda pertenceriam a uma vasilha "côncava extrovertida, comparada ao lábio de baixo ou beiço, é a borda das pequenas bacias; e isto é o que efetivamente se observa nas panelas arqueológicas".

\section{Tratamento de superfície}

As vasilhas Guaraní possuem pouca variação na superfície interna, a maioria alisada com ou sem acabamento, por brunidura, resina, banho, engobo e pintura. A superfície externa, conforme La Salvia e Brochado (1989:46), teria até 8 tipos de acabamentos principais: 1) alisado; 2) digital; 3) ungueal; 4) impresso; 5) estriado; 6) roletado; 7) nodulado; 8) exciso (sendo os três últimos em menor proporção). Eles poderiam ser subdivididos em mais de 50 tipos; e a combinação de dois ou mais tipos resultaria em mais de 100 acabamentos. As vasilhas alisadas que não iam ao fogo eram geralmente pintadas, usadas como copo para beber cauim. Mas as utilizadas para fermentar/armazenar o cauim, como as talhas e cântaros, eram aquecidas por um fogo brando, com 
chama baixa apenas para aquecer a bebida fermentada alcoólica. Apesar desta variedade, Montoya dicionarizou apenas as alisadas e as pintadas na superfície externa, pois seu foco não era o mesmo dedicado a descrever as minúcias dos tratamentos de superfície que interessam aos estudiosos da tecnologia.

Qualquer face externa era traduzida como ajape (T:19) e ape (T:60) superficie; tez; casco; cara. A superfície externa das vasilhas recebia a designação de: 1) japepo ape (T:19) tez exterior da panela e (T:60) lo de fuera de la olla; la superficie; 2) ña'ẽmbe ape (T:358) el plato por de fuera; 3 ) japepo ajape (T:201) la barriga de la olla por de fuera.

A definição de liso vem nos verbetes s̃̃ (T:517) liso e apesỹ (T:62) superficie lisa; tez lisa. A ação é definida pelos verbos jo'a (T:215), amosỹ (T:517, B:32) alisar, e añapes̃̃ (T:62, 517) alisar la superficie. Alisar as duas superfícies da parede vem descrito em: 1) amoapesỹ (T:62) alisar por de fuera; 2) pysỹm (T:479) alisar por de dentro; limpiar bien; acabar de todo punto.

As expressões ambojoja, aisurosurog e ahakapekapevog (B:32) alisar, quitando altibajos, explicam os processos mais avançados de alisamento das paredes (joja (T:216) igualdad). Esta etapa de remoção de altibaixos refere ao alisamento após a união dos roletes. $\mathrm{O}$ alisamento seria com seixos, conchas e com o kuruguãi (T:282) unas habas silvestres gruesas con que alisan la loza (sementes de Mucuna urens Medick). A frase nipysỹ ngatuhávi (T:479) no está bien liso por de dentro, indica a necessidade de se continuar o alisamento.

Após concluir o alisamento costumava-se brunir a superfície lisa, mais comum na face interna, como indicam os verbetes amoendypu e ambojoa (B:32) alisar bruñendo. A brunidura serve para reduzir a porosidade da parede, especialmente nas vasilhas para armazenar líquidos, cozer alimentos e nas vasilhas para servir, como pratos e copos.

Algumas vasilhas antes da queima, após concluir-se o alisamento da superfície externa, recebiam apliques de nódulos de argila com a forma cônica, definidos como hatĩ (T:150) punta; cuerno. A aplicação de muitos cones era chamada amoatĩ atĩ (T:150) poner puntas de hilo, o púas, o puntas na loza cuando la hacen.

Antes da queima a superfície alisada da vasilha que conteria líquidos poderia receber dois tratamentos complementares para vedação e redução da porosidade, especialmente na parte interna (La Salvia e Brochado, 1989:17-18): 1) barbotina: revestimento superficial de argila mais refinada, aplicado antes da queima; 2) banho: revestimento superficial, delgado, proveniente de um caldo ou nata de argila em suspensão na água. Eventualmente poderia receber ambos os tratamentos na superfície externa. Não encontramos verbetes para estes casos.

A pintura com pigmentos era feita quando a vasilha estava totalmente concluída, também antes da queima. A base lisa poderia estar brunida elou com 
banho ou barbotina. Na pintura o fundo era branco, raramente creme. Sobre o fundo iam linhas pretas e vermelhas e, eventualmente, pontos geralmente pretos (ver acima descrição dos pigmentos). A pintura era aplicada somente nas vasilhas que não iam diretamente ao fogo em sua função primária.

O verbo é aikuatia (T:269, B:153, 321) pintar; escribir; dibujar. Quem pinta ou desenha é kuatiahára (B:321) pintor. A escrita, a pintura e o desenho recebiam o nome de kuatia (T:269, B:153, 321) escritura, pintura, dibujo, etc. Adornar, pintar para enfeitar era amombipig ikuatiávo (T:418) adornar pintando e ambopara ikuatiávo (T:396) pintar de varios colores. Como mostra o exemplo, a vasilha pintada era chamada de ña'ẽmbe ikuatiapyre (T:358) loza pintada.

A tinta era denominada como tyũ ou tyrũ (B:380). Era colocada em um "tinteiro" denominado de mba'e ryhũ ryru ou tyhũ ryru (B:380). A aplicação dos pigmentos era feita com pedaços finos e flexíveis de vegetais, pêlos nãoflexíveis, espinhos, etc, especialmente as linhas estreitas (para a tipologia de motivos, ver La Salvia e Brochado, 1989:98-109). Encontramos verbos que poderiam exemplificar a elaboração de linhas, linhas cruzadas e linhas paralelas na pintura de tecidos, no corpo humano e nas vasilhas cerâmicas: hasa; tasa (T:150, 530, B:254) lista; cosa atravesada, lista atravesada; apyrasa (T:76) pasar por encima; hasa parapara (B:254) listado com colores atravessadas (para (T:396) variedad). Em dois verbetes encontramos a representação de dois tipos de pinturas, como a abertura dos favos da colmeia de vespas e como o couro do jacaré: 1) kavatĩ rami ajapo japepo (T:229) pintar las ollas con unos agujeritos a modo de avisperas; 2) japepo jakare (T:200) olla pintada conforme las mallas del lagarto e ambojakare che japepo (T:200) pintar así las ollas.

Depois da queima, as vasilhas para conter líquidos que não eram utilizadas sobre o fogo poderiam receber resina vegetal para impermeabilização na parede interna. As pintadas também eram resinadas, apenas onde havia a pintura. Os espanhóis chamavam de breu e verniz as resinas vegetais, exatamente como traduziu Montoya: yvyra ysy (T:652, B:350) resina. Ele usa como exemplo a kuri'yvysy (T:281, B:77) brea de pino, a resina da árvore Araucaria angustifolia. O verbo é mõng (T:317) cosa pegajosa; brear; pegar con brea. A fixação da resina ocorria com o aquecimento gradativo e indireto da vasilha próxima de uma pequena fogueira, aquecia-se mais a resina para deixá-la líquida. $\mathrm{O}$ ato de resinar está nos verbetes: 1) aikupemõng (B:77) brear por de dentro; 2) aypi mõng kambuchi (T:317) brear, o poner barniz al cántaro por de dentro. E usar a resina de araucária é amongy kuri'yvysy; ajo'og kuri'yvysy pype (B:77) brear; passar a resina por dentro é aikupemõng; amongy kuri'yvysy ipy rupi (B:77) brear por de dentro. O verbete ña'ẽmbe imoendypúpy (T:358) "prato vidrado", representa as vasilhas que receberam o acabamento interno com resinas. Resta a questão: quais as alternativas para resinas vegetais nas 
áreas distantes das florestas de araucária? Uma possibilidade é a yvyra ysy (almacegueira, breu branco) Protium heptaphyllum, árvore cuja resina é usada pelos Guaraní para fins medicinais (Gatti 1985:141, 148) e, devia ser, como foi para os Tupinambá, utilizada para resinar e envernizar as cerâmicas pintadas.

A pintura esmaecida, enfraquecida, apagada e perdida, comum nas vasilhas usadas, aparece nas expressões amomeguã; amboai; aimonã; ambogue; amboje'og (B:147) deshacer, echar a perder letra, pintura.

\section{Contextos de uso das vasilhas}

Montoya selecionou algumas expressões e verbos sobre o uso das vasilhas, tanto sobre o uso sobre o fogo e os seus efeitos sobre a vasilha, quanto para limpá-las e usá-las para servir alimentos e bebidas.

\section{Queimar e quebrar}

Sobre a queima das vasilhas, quando elas são confeccionadas, não há referência explícita. Porém, existe uma referência do uso da panela colocando-a sobre o fogo para alguma cocção: añoño japepo (T:377) poner la olla al fuego (ñoño (T:377, B:325) poner). E para afastar a vasilha do fogo, para deixar seu conteúdo na temperatura de manuseio para processar, ou para comer: aroguejy japepo (T:131) apartar la olla del fuego, o bajarla de otra cosa (de guejy (T:131) bajada; aguejy (T:131) yo bajo; aguejy (B:46) apearse).

Para a panela com água fervente sobre o fogo: opupu japepo (B:224) hervir la olla; okumbekumbeg, opupuete (B:224) hervir la olla a borbollones; pytu y ei (T:482) agua del vapor de la boca, y de la olla caliente. Uma panela poderia ser usada para cozinhar várias vezes: ambojoupague (T:597) cocer en una misma olla uno tras otro.

A panela com seu conteúdo quente poderia exalar vapor pelos poros da superfície externa: japepo timbo; japepo pytu (B:392) vaho de la olla e (T:482) vapor de la olla caliente; (de timbo (T:581) vaho; pytu (T:482) vaho, calor del fuego, aliento, vapor). Também poderia gotejar após a condensação do vapor: oẽ japepo (T:116) rezúmase la olla; oyga kambuchi (T:635) rezúmase el cántaro.

Depois de ser afastada do fogo ou do fogo ter se extinguido, a panela teria sua temperatura reduzida: ijapyryve japepo (T:78) no hierve más la olla.

$\mathrm{O}$ uso sobre o fogo deixaria a superfície externa coberta por fuligem, especialmente da metade para baixo da vasilha: apekumã; kumã (T:62, 274, B:226) hollín; japepo kumã; japepo rũ; japepo apekumã (T:201, 274, B:226) tizne; hollín. Também poderia queimar o conteúdo, especialmente nas vasilhas maiores, deixando crostas grudadas na superfície interna: 1) ipyjare (T:193) lo que se pegó cocido a la olla (de ja (T:193) pegar); 2) amopiche jykysy (B:339) 
quemar el guisado.

Encontra-se uma associação entre a quebra da vasilha e o fogo: tata ojapiti kambuchi (T:69) el fuego quebró la olla. Porém, não há como definir se a quebra foi durante a queima ou no uso cotidiano. Vem de apiti (T:69) quebrar en pedazos, tendo como exemplo a descrição de uma vasilha quebrada: ajapiti kambuchi (T:69, B:338) hacer pedazos la olla. Também vem de ajoka (B:338) quebrar, exemplificado por ajoka kambuchi (B:338) quebrar vaso; e com o sentido de causar um dano, quebrando: ajambogua (T:2) quebrar cántaro, o calabazo de água.

Durante a preparação de alimentos e bebidas eram usados alguns equipamentos para mexer o conteúdo, como pazinhas e colheres: aipyvu, aipykúi, aipyguara (B:352) revolver en olla. Eles poderiam deixar marcas raspadas nas paredes internas das vasilhas, incluindo-se: 1) yvyra pehẽ (T:653) paleta para revolver la olla; (B:121) cuchara o espátula de hacer mazamorra; 2) tyjúi ogkáva (T:605, B:187) espumadera; 3) yvyra kuipe (T:274) cuchara de palo.

O fragmento era chamado ñapesẽ ( $\mathrm{T}: 361)$ tiesto, de pedaço, parte: pes̃ (T:407, B:308, 312) e pehẽ (T:403) pedazo. Por exemplo, pedaço de prato: ̃̃a'̃̃ pesẽngue (B:380) tiesto. E o coletivo: pesẽnta (T:408, B:312) muchos pedazos.

Montoya deu exemplos para a quebra de partes específicas das vasilhas.

Para a base: 1) japepo rugua pog (T:593) quebrose el asiento de la olla; 2) japepo rugua ambopog (T:593) quebrose el asiento de la olla; quité el asiento de la olla. Note que a frase anterior mostra a intenção de quebrar, tirando a base ou um pedaço dela.

Para a borda e lábio: 1) kambuchi juru chacha (T:221) cántaro que tiene la boca rota (juru (T:220, B:74) boca e chacha (T:109) rechinar la cosa (como el instrumento que está hendido, o despegado); ahembeka ña'ẽ (B:338) quebrar labio del plato (mbeka, peka (T:330, 404) abertura, no sentido de forçar, rachar, quebrar); 3) ahembeyvo; ahembeka (B:151) desportillar la boca de vaso, etc., registro para a vasilha quebrada na borda, "desbeiçada":

\section{Tapar e destapar}

As vasilhas poderiam ser cobertas por vários motivos, mas não encontramos exemplos históricos ou etnográficos, salvo o uso de vasilhas como opérculo nos enterramentos com "urnas funerárias". O léxico oferece exemplos, com as expressões para tampa, mas sem especificar como era a cobertura ou sua matéria: japepo asojáva; japepo rovapy tỹmbáva; japepo rovapy asojáva (T:90, 201) tapadera de la olla; japepo asoja (B:99) cobertera de olla. O verbo tampar e cobrir foram registrados como: aho'i (T:15), aso'i (T:90), ahovapy rahó'i (T:589) tapar, cubrir, encubrir; ahovapy tỹ (T:173, 589) tapar. As tampas foram descritas como cobertera ou tapadera em asojáva (T:90, B:205), 
hovapy rasojáva (T:589), hovapy tỹmbáva (T:173, 589), com o sentido de cobrir a superfície, a "cara" de uma abertura (de tova (T:586) e tovapy (T:588) rostro, cara, haz, cara de la cosa, superficie [el principio del rostro]). Literalmente, japepo rovapy asojáva traduz-se "panela + área da superfície + tampa" (tampa da área da superfície da boca da panela).

Destampar também possui várias acepções: ajasojavo (B:151), ahovapy tỹmbo'i (T:173, 589, B:151), ahovapy tỹmbavog (T:173, 589, B:151) destapar; asojávo (T:90) destapar; descubrir lo tapado. A ação de destampar possui alguns exemplos: ahovapytymbavog, ahovapysojavog, ahovapysope'a, aovasojamboi, ahovapyasojambovy (B:7) abrir, destapar como a cântaro, etc.

Para um modo específico de tampar uma vasilha, destacam-se as expressões ahovapypeteg, ahovapymou'ũ, ahovapychy (B:165) embarrar la boca del vaso. No caso, significa colocar o barro na parede externa ao redor da abertura da vasilha: ajapeteg (B:165) embarrar (ajape (T:18) la superficie, o tez, casco; japepo ajape (T:19) la tez exterior de la olla). Seria para assentar uma vasilha sobre outra para fermentar o cauim nas condições adequadas de pressão (Noelli e Brochado, 1998:124), em sobreposição semelhante à encontrada nos enterramentos. No vocabulário da língua brasílica, escrito no final do século XVI, o verbete açobapigtec (VLB 1:52) barrar como as panelas emq. se guarda o uinho, oferece mais detalhes sobre esta técnica de vedar duas vasilhas sobrepostas para fermentar o cauim, como faziam os Tupinambá. As tampas das talhas usadas durante o período de fermentação do cauim também poderiam ser feitas com trançados bem vedados ou couros, cingidos com cordas ou tiras de couro na boca dos kambuchi.

\section{Limpeza}

A remoção das crostas queimadas durante a cocção dos alimentos, ao serem removidas na limpeza, poderiam deixar marcas de uso na superfície interna ao serem removidas por raspagem e esfregação: 1) kysy (T:287) refregón, revolver; ambokysy (T:287) menear, refregar; 2) kyty (T:288) refregar, limpiar; 3) aikyty (T:288) yo refriego, limpio. Daí limpar dentro, esfregando: ambopykytĩ (T:456) limpiar por dedentro.

A limpeza das vasilhas pautava parte das ações cotidianas para a manutenção dos utensílios domésticos. Encontramos informações que indicam modos de remover os resíduos culinários após o uso, basicamente aguando por dentro as vasilhas: 1) aipysỹmbo ña'ẽmbe; ña'ẽmbe pysỹmbo (T:456, 479) limpiar bien los platos; 2) aipyereko; amongure kambuchi ihéita; ambokosokoso ihéita (B:173) enjaguar vasos.

O verbo pysy (T:478) bañar, compõe a maioria das expressões que exemplificam a limpeza das vasilhas com água. Também encontramos 
descrições de limpeza da parte interna de algo nos verbetes aipysỹmbo (T:456) limpiar por dedentro, pysỹmbo (T:479) limpiar por dedentro. Encontramos também uma descrição sobre esvaziar a vasilha escorrendo o seu conteúdo, sem definir se era alimentar ou água da limpeza: amondyky (B:184) escurrir la vasija. A limpeza interna das vasilhas poderia ser complementada esfregando as paredes com uma epífita, definida por Montoya como estopa e esponja: 1) yvyra ygáu (T:636) estopa de los árboles; 2) ygáu (B:187) esponja. É a bromeliácea Tillandsia usneoides L. (Gatti, 1985: 49, 125), chamada de barba de pau ou de velho (barba de viejo no Paraguai e Argentina).

\section{Guardar as vasilhas}

Não existem informações específicas sobre como guardavam e organizavam as vasilhas, mas as suas casas e áreas de atividade deveriam ter uma variedade e quantidade considerável de peças para diferentes funções. Encontramos a definição para "armário de louça", que não deveria servir apenas para guardar os pratos: ña'ẽ rupáva, ña'ẽmbe rendáva, ña'ẽmbe rendatýba (B:33) almario de loza, nome que deriva de mba'e rupáva (B:256) lugar donde se guarda algo.

\section{Considerações Finais}

A construção de um artigo a partir de 445 palavras e frases do vocabulário sobre vasilhas cerâmicas é mais do que uma alternativa à falta de fontes históricas e etnográficas. Com efeito, é um exercício no limite do vazio epistemológico para superar o esquecimento de um conhecimento tradicional multimilenar ofuscado com as mudanças impostas pelas vicissitudes da história colonial. No presente, em certas comunidades, alguns Guaraní decidiram voltar a fazer vasilhas cerâmicas, procurando ressignificar alguns conhecimentos atuais sobre usos e formas. Mas enfrentam dificuldades para superar entre eles a longa ausência da produção de vasilhas cerâmicas e o desaparecimento das protagonistas deste campo do saber. Com a morte das mulheres que detinham a expertise prática, a capacidade para oferecer a orientação prática e teórica na aprendizagem da tecnologia cerâmica e da memória do conhecimento tradicional ficaram reduzidas. A linguagem da cerâmica registrada por Montoya pode estimular estudos entre os Guaraní atuais interessados na cerâmica. Seria uma oportunidade para reunir experiências do passado e do presente; seria como um sopro poético das tradições passadas insuflando, inspirando vigor, às práticas tecnológicas da atualidade das comunidades Guaraní.

O conteúdo apresentado no artigo poderá ser avaliado e utilizado conforme a disciplina científica de cada um. Mas desde a perspectiva da linguística histórica comparada, podemos contrastar e cotejar o vocabulário coligido por Montoya com os vocabulários da cerâmica das 10 famílias linguísticas do 
tronco Tupí. Este contraste oferecerá empiria sobre o desenvolvimento das classes funcionais na longa duração de 5 mil anos desde o Proto-Tupí, as quais possibilitaram o processamento de plantas, a criação de novas dietas e maneiras de servir o cardápio. O vocabulário Guaraní, desde que não confinemos as fontes - e inclusive as linguísticas! - nos limites de uma única disciplina, oferece muitas possibilidades de encontrar pareamentos compatíveis nos vocabulários das demais 70 línguas do tronco Tupí (Rodrigues e Cabral, 2012). Talvez as línguas Tupinambá, Asuriní do Xingu, Suruí e Juruna ofereçam no presente léxicos mais completos, e possibilidades de exercícios interessantes a serem descobertos. Também seria importante vasculhar as fontes linguísticas, históricas e etnográficas sobre as demais famílias do tronco Tupí, para deslocar o peso atual da família Tupí-Guaraní como referência quase absoluta do conhecimento tecnológico e arqueológico da cerâmica. É importante procurar um equilíbrio que permita uma compreensão mais adequada do que representou a cerâmica para cada um dos povos Tupí.

Adotando-se uma perspectiva interdisciplinar, o problema de pesquisa é verificar se as regularidades linguísticas se evidenciam nos conjuntos artefatuais de todas as famílias, como no caso dos Tupí-Guaraní. A regularidade da morfologia nas principais classes funcionais encontradas nos sítios arqueológicos da imensa área ocupada pelos Guaraní é uma evidência de que a regularidade linguística também ocorria: se as vasilhas eram feitas e usadas de modos específicos, é provável que conservassem seus nomes e as linguagens afins. A base empírica e teórica desta perspectiva é o trabalho de Aryon Rodrigues (2007, 2010), que mostrou através de reconstruções fonéticas pela linguística histórica comparada que os Tupí são ceramistas desde o Proto-Tupí. As tabelas 2 e 3 mostram a reconstrução fonética da palavra panela, uma vasilha emblemática para os Tupí, uma palavra do vocabulário básico que foi conservada desde o Proto-Tupí. Mesmo com variações, a fonética revela um aspecto estrutural e estruturante na manutenção do nome panela na longa duração, em 7 das 10 famílias linguísticas, incluindo a família Tupí-Guaraní, onde a língua Guaraní foi incluída no ramo I (faltam dados nas famílias Puruborá, Mondé e Arikém). No cerne do modelo genético de Rodrigues (1985:34) está a hipótese, aceita por diversas tendências teóricas que investigam a linguística histórica da família Tupí-Guaraní, "de que as línguas em questão sejam manifestações diferenciadas do que foi no passado uma mesma língua e que as propriedades compartilhadas sejam a herança comum conservada sem diferenciação ou apenas diferenciações menos profundas". Este componente estrutural marcado no vocabulário básico da cultura material explicaria uma das causas das semelhanças tecnológicas e funcionais entre tantos conjuntos artefatuais. A tabela 4 mostra o nome da panela em 15 línguas da família Tupí-Guaraní. 
Tabela 2: Reconstrução fonética da palavra panela

\begin{tabular}{c|l|l|c} 
Proto-Língua & \multicolumn{1}{|c|}{ Região } & \multicolumn{1}{c|}{ Panela } & Fonte \\
\hline Proto-Tupí & Rondônia & $* *$ wa?ẽ & \multirow{2}{*}{ Rodrigues 2007} \\
\cline { 1 - 3 } Proto-Tupí-Guaraní & $?$ & $*$ ja?ẽ &
\end{tabular}

Tabela 3: Panela nas famílias do Tronco Tupí

\begin{tabular}{c|c|c} 
Famílias & Panela & \multirow{2}{*}{ Fonte } \\
\hline Juruna & warẽ & \multirow{3}{*}{ Rodrigues 2007 } \\
\hline Munduruku & ware & \\
\hline Awetí & ta?ẽ & \\
\hline Tupí-Guaraní & ja?ẽ & \\
\hline Tuparí & warẽ &
\end{tabular}

Tabela 4: relação forma/função das vasilhas cerâmicas da família Tupí-Guaraní

\begin{tabular}{|c|c|c|c|c|c|}
\hline Língua & Região & $\begin{array}{c}\text { Cozinhar } \backslash \\
\text { Panela }\end{array}$ & $\begin{array}{c}\text { Armazenar } \\
\text { líquidos } \backslash \\
\text { cauim } \backslash \\
\text { Talha }\end{array}$ & $\begin{array}{c}\text { Servir } \backslash \\
\text { Consumir } \\
\text { Prato }\end{array}$ & Fonte \\
\hline \multicolumn{6}{|l|}{ Ramo 1} \\
\hline Guaraní & $\begin{array}{l}\text { Brasil } \\
\text { Meridional } \backslash \\
\text { Paraguai } \\
\text { Argentina } \backslash \\
\text { Uruguai }\end{array}$ & Japepó & $\begin{array}{l}\text { kambutsí } \\
\text { k } \\
\text { kãmbu't fí }\end{array}$ & ja'ẽmbe & Montoya 2011 \\
\hline Chiriguano & Bolívia & japépo & kambúfí & jáẽ & $\begin{array}{l}\text { Giannecchini } \\
1916 \\
\end{array}$ \\
\hline Tapieté & Bolívia & japépo & & ña'ẽ’õ & González 2005 \\
\hline \multicolumn{6}{|l|}{ Ramo 2} \\
\hline Sirionó & Bolívia & $\begin{array}{l}\text { ñéo } \\
\text { ['ñiõo] }\end{array}$ & & & Holmberg 1960 \\
\hline \multicolumn{6}{|l|}{ Ramo 3} \\
\hline $\begin{array}{c}\text { Língua } \\
\text { Geral } \backslash \\
\text { Amazonas } \\
\end{array}$ & $\begin{array}{l}\text { Baixo } \\
\text { Amazonas }\end{array}$ & japepú & $\begin{array}{l}\text { kamusí, } \\
\text { kamutí }\end{array}$ & jaẽ & Stradelli 1929 \\
\hline Tupinambá & $\begin{array}{l}\text { Litoral } \\
\text { Brasileiro, }\end{array}$ & ja'ẽpepó & kamisí & ja'ẽ & VLB \\
\hline Ramo 4 & & & & & \\
\hline
\end{tabular}




\begin{tabular}{|c|c|c|c|c|c|}
\hline Língua & Região & $\begin{array}{l}\text { Cozinhar } \backslash \\
\text { Panela }\end{array}$ & $\begin{array}{c}\text { Armazenar } \\
\text { líquidos } \backslash \\
\text { cauim } \backslash \\
\text { Talha }\end{array}$ & $\begin{array}{c}\text { Servir } \backslash \\
\text { Consumir } \backslash \\
\text { Prato }\end{array}$ & Fonte \\
\hline Tapirapé & Tapirapé & t fã'?ẽ & & & Baldus 1970 \\
\hline $\begin{array}{l}\text { Asuriní do } \\
\text { Tocantins }\end{array}$ & Tocantins & sa'é & & & Nicholson 1982 \\
\hline Tembé & Maranhão & zapepó & kamutí & & Rice 1934 \\
\hline \multicolumn{6}{|l|}{ Ramo 5} \\
\hline $\begin{array}{l}\text { Asuriní do } \\
\text { Xingu }\end{array}$ & Xingu & japepaí & & ja’é & Silva 2000 \\
\hline \multicolumn{6}{|l|}{ Ramo 6} \\
\hline Parintintin & Tapajós & japepó & kamabuí & jaetíngy’á & Betts 1981 \\
\hline $\begin{array}{c}\text { Tupí- } \\
\text { Kawahíb }\end{array}$ & Madeira & japepoí & & & \\
\hline Apiaká & Tapajós & jẽpepó & & & Coudreau 1897 \\
\hline Kayabí & Tapajós & japepó & & & Weiss 1988 \\
\hline \multicolumn{6}{|l|}{ Ramo 7} \\
\hline Kamayurá & Xingu & ja'ẽ & & & Baldus 1970 \\
\hline \multicolumn{6}{|l|}{ Ramo 8} \\
\hline Kaapor & Maranhão & & kamuxĩ & & $\begin{array}{l}\text { Kakumasu e } \\
\text { Kakumasu } 1988\end{array}$ \\
\hline
\end{tabular}

Paralelamente é necessário construir um caminho semelhante na comparação das vasilhas cerâmicas das 70 línguas. As coleções arqueológicas melhor conhecidas são as Guaraní e Tupinambá; as coleções etnográficas mais estudadas são as Asurini do Xingu, Juruna, Suruí e Parakanã. Existem ainda coleções menores, com poucas ou apenas uma vasilha para várias línguas e existe uma grande quantidade de iconografias e fotografias em arquivos e publicações que precisam ser pesquisadas. Um exercício de arqueologia reversa comparada, indo das coleções do presente para as coleções do passado, poderia associar à deriva genética linguística com a diferenciação das vasilhas e encontrar os marcadores que possam permitir identificar no passado a autoria do registro arqueológico em nível de língua ou família.

A partir da nossa experiência de campo na arqueologia, da visita a 150 instituições nacionais e internacionais para registrar vasilhas inteiras arqueológicas e etnográficas, de ler milhares de fontes históricas, etnográficas, linguísticas arqueológicas; e, finalmente, depois de examinar milhares de fragmentos cerâmicos, concluímos que existe um imenso potencial de pesquisa nas coleções, cujo acúmulo provém do século XIX. Tanto quanto os sítios arqueológicos, este acúmulo oferece chances e atalhos para compreender uma 
parte dos processos históricos dos Tupí em relação a sua origem e expansão geográfica. Podem indicar, pois, quais áreas teriam maior potencial para novas descobertas e estimular novas ideias.

Um outro veio de pesquisa é aquele sugerido pelo título de nosso artigo. As regularidades linguísticas e artefactuais materializam aspectos da ontologia Guaraní; elas são práticas do ñande reko, que lhes permitiu transmitir suas milenares tradições e mantê-las no presente. Se, como quer Ingold (2013: 17-32), o ambiente não tem objetos, é porque, como evidencia o caso dos Guaraní, a morfologia da cerâmica não se separa dos corpos das pessoas; tal inseparabilidade entre corpo e objetos, entre os Guaraní, simetrizam humanos e não humanos num mesmo plano ontológico. Daí que, como a mão humana, a vasilha agarra, pega ou toma o conteúdo que se despeja nela. Os objetos, assim como a linguagem (sensu Barthes 2008), são feitos para agarrar. Por isso há poética, uma beleza que consideramos tocante numa vasilha Guaraní: ela é verso encarnado, verbo feito de barro.

\section{Agradecimentos}

À Ana Suelly Cabral pela revisão cuidadosa e fraterno incentivo para finalizar este artigo suspenso desde 1993, quando da sua primeira escrita por Noelli e Brochado, em Porto Alegre. Em Londrina (2001), o saudoso amigo Aryon Rodrigues sugeriu uma colaboração para ampliar o escopo do manuscrito para um estudo de linguística comparada na família Tupí-Guaraní, mas não conseguimos unir esforços por motivos alheios a nossa vontade. Em 2017 foi reescrito em São Paulo; e finalizado em 2018 por Corrêa e Noelli, em Teresina e na Pindorama, em Timon. Às leituras e generosas sugestões de Fabíola Andréa Silva, Amílcar de Mello D’Ávila, Marianne Sallum, Lúcio Menezes Ferreira, Noélia Bortolloto, Andres Gascue, Silvana Suze, Eduardo Bespalez, Lorena L. W. G. Garcia e Mariano Bonomo.

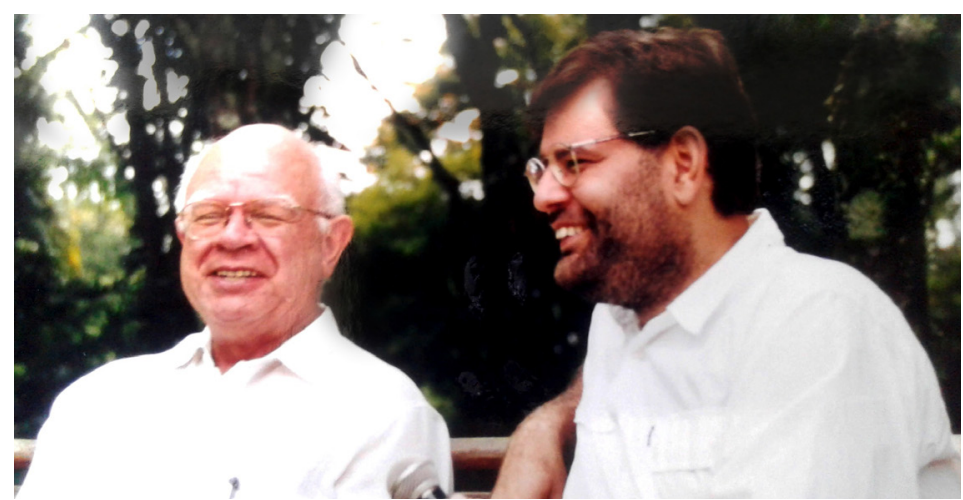

Aryon Dall'Igna Rodrigues e Francisco Noelli, I Encontro de Línguas Jê, Londrina-PR, fevereiro de 2001. Foto de Luis Carlos Tavares de Sá. 


\section{Referências}

Azara, F. Geografía física y esférica de las Provincias del Paraguay y Misiones Guaraníes. Año de MDCCXC. Anales del Museo Nacional de Montevideo, 1:1-610. 1904.

Azara, F. Descripción e Historia del Paraguay y del Río de la Plata. Buenos Aires, Editorial Bajel.

Betts, L. V. D. 1981. Dicionário Parintintin-Português, Português-Parintintin. Brasília: Summer Institute of Linguistics. 1943.

Baldus, H. 1970. Os Tapirapé. Tribo do Brasil Central. São Paulo: Cia Editora Nacional.

Barthes, R. 2008. Aula. São Paulo: Cultrix.

Bonomo, M.; Angrizani, R. C.; Apolinaire, E.; Noelli, F. S. 2015. A model for the Guaraní expansion in the La Plata Basin and littoral zone of southern Brazil. Quaternary International, 356:54-73.

Brochado, J. P. 1984. An ecological model of the spread of pottery and agriculture into Eastern South America. Urbana-Champaign: University of Illinois at UrbanaChampaign. (Tese de doutorado).

Brochado, J. P.; Monticelli, G.; Neumann, E. 1990. Analogia etnográfica na reconstrução gráfica das vasilhas Guarani arqueológicas. Veritas, Porto Alegre, 35(140):727-743.

Brochado, J. P.; Monticelli, G. 1994. Regras práticas na reconstrução gráfica da cerâmica Guarani por comparação com vasilhas inteiras. Estudos Ibero-Americanos, 20(2):107-118.

Cabeza De Vaca, A. A. 1906. Naufragios y comentarios. Madrid, Librería General de Victoriano Suárez. 2 v.

Corrêa, A. A. 2017. Datações na bibliografia arqueológica brasileira a partir dos sítios Tupí. Cadernos do Lepaarq, 14(27):379-406.

Corrêa, A. G. 2014. Pindorama de Mboia e Iakaré: continuidade e mudança na trajetória das populações Tupí. São Paulo: Universidade de São Paulo (Tese de doutorado).

Covarrubias Orozco, S. 1611. Tesoro de la lengua Castellana, o Española. Madrid: Luiz Sanchez.

Diccionario De Autoridades, 1726-1739. Madrid: Real Academia Española. 6 v.

D’Orbigny, A. 1944. El hombre americano considerado en sus aspectos fisiológicos y morales. Buenos Aires: Editorial Futuro.

Ford, J. A. 1962. Método cuantitativo para estabelecer cronologias culturales. Washington D.C.: Unión Panamericana.

Galloway, P. 2006. Material culture and text: Exploring the spaces within and between. In: HALL, M; SILLIMAN, S. (eds). Historical Archaeology. Blackwell Publishing, Oxford, pp. 42-64.

Gatti, C. 1985. Enciclopedia Guarani-Castellano de ciencias naturales y conocimientos paraguayos. Asunción: Editorial Nuevo. 
Giannecchini, D. 1916. Diccionario Chiriguano-Español y Español-Chiriguano. Tarija. González, H. 2005. A grammar of Tapieté (Tupi-Guarani). Pittsburg: University of Pittsburgh (Tese de Doutorado).

Guash, A.; Ortiz, D. 1986. Diccionario Castellano-Guaraní, Guaraní-Castellano. Asunción: CEPAG.

Guha, R. 1997. Dominance without hegemony: History and power in Colonial India. Cambridge: Harvard U. P.

Holmberg, A. 1960. The nomads of the long bowl. Chicago: Chicago University Press.

Ingold, T. 2013. Making: Anthropology, Archaeology, Art and Architecture. London: Routledge.

Kakumasu, J. Y.; Kakumasu, K. Dicionário por tópicos Urubu-Kaapor-Português. Brasília: Summer Institute of Linguistics. 1988.

La Salvia, F.; Brochado, J. P. 1989. Cerâmica Guarani. Porto Alegre: Pozenato Arte \& Cultura.

Meggers, B: J.; Evans, C. 1970. Como interpretar a linguagem da cerâmica. Washington, DC: Smithsonian Institution.

Melià, B: 1986. La población Guaraní del antiguo Guaira en la historia primera (15411632). In: B: Melià. El Guaraní conquistado y reducido. Asunción, CEADUC $\backslash$ CEPAG. pp. 60-89.

Métraux, A. 1928. La civilisation matérièlle des tribus Tupi-Guarani. Paris, Librarie Orientaliste.

Montoya, A. R. 1639. Tesoro de la lengua Guaraní. Madrid: Juan Sanchez.

Montoya, A. R. 1876a. Arte de la lengua guarani, ó mas bien tupi. v. 1. Viena: Faesy y Fric.

Montoya, A. R. 1876B: Arte de la lengua guarani, ó mas bien tupi. v. 2. Viena: Faesy y Fric.

Montoya, A. R. 1876c. Tesoro de la lengua Guaraní. Leipzig, B:G. Teubner.

Montoya, A. R. 1876d. Bocabulario de la lengua Guaraní. Leipzig, B:G. Teubner.

Montoya, A. R. 1994. Arte y vocabulario de la lengua Guaraní. Edición de Silvio Liuzzi. Madrid: Cultura Hispanica.

Montoya, A. R. 2002. Vocabulario de la lengua Guaraní. Asunción: CEPAG.

Montoya, A. R. 2011. Tesoro de la lengua Guaraní. Asunción: CEPAG.

Nicholson, V. 1982. Breve estudo da língua Asuriní. Brasília: Summer Institute of Linguistics.

Noelli, F. S. 1993. Sem Tekohá não há Tekó (em busca de um modelo etnoarqueológico da subsistência e da aldeia Guarani aplicado a uma área de domínio no delta do Jacui-RS). Porto Alegre: IFCH-PUCRS (Dissertação de Mestrado).

Noelli, F. S. 1994. El Guaraní agricultor. Acción - Revista Paraguaya de reflexión y diálogo, 144:17-20. 
Noelli, F. S. 1998a. Aportes históricos e etnológicos para o reconhecimento da classificação Guaraní de comunidades vegetais no século XVII. Fronteiras. Revista de História, 2:275-296.

Noelli, F. S. 1998B: Múltiplos usos de espécies vegetais pela farmacologia Guaraní através de informações históricas. Diálogos, 2:177-199.

Noelli, F. S.; Brochado, J. P. 1998. O cauim e as beberagens dos Guaraní e Tupinambá: equipamentos, técnicas de preparação e consumo. Revista do Museu de Arqueologia e Etnologia, 8:117-128.

Paucke, F. 1944. Hacia alla y para cá (Una estada entre los indios Mocobíes, 17491767). 3 v. Tucumán: Universidad Nacional de Tucumán.

Rice, F. J. D. 1934. O idioma També (Tupí-Guaraní). Journal de la Société des Américanistes, 26:109-152.

Rodrigues, A. D. 1984-1985 As relações internas na família Tupi-Guarani, Revista de Antropologia, 27-28:33-53.

Rodrigues, A. D. 2007. As consoantes do Proto-Tupí. In: A. S. A. C. Cabral; A. D. Rodrigues. (org). Linguas e Culturas Tupí. Campinas/Brasília: Curt Nimuendajú/ LALI. pp. 167-203.

Rodrigues, A. D. 2010. Linguistic reconstruction of elements of prehistoric Tupí culture. In: E. B. Carlin; S. van der Kerke (org). Linguistics and archaeology in the Americas: the historization of language and society, v. 2. Leiden: Brill. pp. 1-10. 2010.

Rodrigues, A. D.; Cabral, A. S. 2012. Tupían. In: Campbell, L.; Grondona, V. (eds). The indigenous languages of South America, v. 2. Boston: Mouton de Gruyter. pp. 495-574.

Silva, F. A. 2000. As Tecnologias e seus Significados. São Paulo: Universidade de São Paulo (Tese de Doutorado).

Silva, F. A.; Noelli, F. S. 2017. Arqueologia e Linguística: Construindo as trajetórias histórico-culturais dos povos Tupí. Crítica e Sociedade: Revista de Cultura Política, 7(1):55-87.

Stradelli. H. 1929. Vocabulário Nheengatu-Português e Português-Nheengatu. Rio de Janeiro: Instituto Histórico e Geográfico Brasileiro.

Torres, C.; Gómez Martinez, S.; Ferreira, M. B. 2003. Os nomes da cerâmica medieval: Inventário de termos. Actas das $3^{\text {c }}$ Jornadas de Cerâmica Medieval e Pós-Medieval. Tondela: Câmara Municipal de Tondela. pp. 125-134.

VLB 1952. Vocabulário na Língua Brasílica. São Paulo: Boletim 137 da Faculdade de Filosofia, Ciências e Letras da Universidade de São Paulo. 